Article

\title{
Operational Flexibility of a CFB Furnace during Fast Load Change-Experimental Measurements and Dynamic Model
}

\author{
Jens Peters * ${ }^{(}$, Falah Alobaid and Bernd Epple \\ Institute for Energy Systems and Technology, Technical University of Darmstadt, Otto-Berndt-Straße 2, \\ 64287 Darmstadt, Germany; falah.alobaid@est.tu-darmstadt.de (F.A.); bernd.epple@est.tu-darmstadt.de (B.E.) \\ * Correspondence: jens.peters@est.tu-darmstadt.de; Tel.: +49-(0)-6151-16-22689; Fax: +49-(0)-6151-16-22690
}

Received: 24 July 2020; Accepted: 24 August 2020; Published: 28 August 2020

\begin{abstract}
The share of power from fluctuating renewable energies such as wind and solar is increasing due to the ongoing climate change. It is therefore essential to use technologies that can compensate for these fluctuations. Experiments at $1 \mathrm{MW}_{\text {th }}$ scale were carried out to evaluate the operational flexibility of a circulating fluidized bed (CFB) combustor during transient operation from $60 \%$ to $100 \%$ load. A typical load following sequence for fluctuating electricity generation/demand was reproduced experimentally by performing 4 load changes. The hydrodynamic condition after a load change depends on if the load change was in positive or negative direction due to the heat stored in the refractory/bed material at high loads and released when the load decreases. A 1.5D-process simulation model was created in the software APROS (Advanced Process Simulation) with the target of showing the specific characteristics of a CFB furnace during load following operation. The model was tuned with experimental data of a steady-state test point and validated with the load cycling tests. The simulation results show the key characteristics of CFB combustion with reasonable accuracy. Detailed experimental data is presented and a core-annulus approach for the modeling of the CFB furnace is used.
\end{abstract}

Keywords: $\mathrm{CFB}$ combustion; operational flexibility; load transients; fluctuating electricity generation; lignite; renewables

\section{Introduction}

Climate change due to high $\mathrm{CO}_{2}$ emissions has led to a substantial increase in the proportion of electricity generated from renewable sources around the world in the last two decades [1]. Wind and solar energy account for a large share of these renewables. These two energy sources have the disadvantage that they are not suitable to provide baseload and, depending on the conditions, the electricity generated can fluctuate strongly and rapidly. There is a demand for highly flexible technologies to ensure the energy supply with low $\mathrm{CO}_{2}$ emissions at the same time. Circulating fluidized bed (CFB) combustion can be a key element in the future energy supply, as it can combust a high spectrum of solid fuels of different origins such as biomass and waste-derived fuels [2-5]. The technology comes with a high combustion efficiency [6] and with low emissions of $\mathrm{SO}_{2}$ and $\mathrm{NO}_{x}[7,8]$. CFB boilers can operate over a wide range of thermal loads and are therefore capable of compensating a fluctuating electricity demand.

The high fuel flexibility is made possible by a large mass of inert particles in the reactor, which can compensate for fluctuations in the fuel composition. However, the high thermal inertia of this material has a negative impact on the load following capability and especially the cold start-up of CFB combustors [6]. During transients from medium to high load, ramp rates of up to $7 \% \mathrm{MCR} / \mathrm{min}$ (MCR: 
maximum continuous rating) are claimed to be possible [9]. However, modern large-scale CFB boilers, such as the Polish CFBC unit at Łagisza have load following capabilities of up to $4 \% \mathrm{MCR} / \mathrm{min}$, which is similar to pulverized coal power plants [6]. The need for even faster load change rates increases with the rising share of renewable energies. Therefore, there is a demand to investigate novel concepts to accelerate load ramps in CFB combustion. For example, thermal energy storage systems can be used to rapidly extract a large amount of energy from the furnace [10]. Another option is to apply smart control strategies for the water/steam side and the fuel and air mass flow [11-13]. To examine novel concepts, experimental investigations are necessary but often very expensive, especially on a large scale. Computational fluid dynamics (CFD) simulations, on the other hand, are complicated and require a lot of computing time, even though they are often the only way to study CFB combustion inside a furnace in detail [14-17]. One-dimensional dynamic process models offer the advantage of low computing time and an appropriate accuracy to evaluate new approaches before they are tested in an industrial-scale boiler $[18,19]$. The commercial software APROS is used extensively in industry and research for the dynamic process modeling of thermal power plants $[12,20,21]$.

So-called 1.5-dimensional core-annulus models take into account the mass and heat flow from the core to the annulus and vice versa. Particles and particle clusters stream upwards in the core region of the furnace, while they stream downwards in the annulus, due to the low gas velocities near the wall. This internal circulation of solids in the furnace is up to 2 times higher than the external circulation via cyclone and loop seal [22]. The convective heat transfer to the walls of the furnace is mainly determined by the mass flow from the core to the annulus and from the annulus to the core, so it is important to take this mechanism into account. However, the only way to prove the suitability of process models for dynamic investigations is by validation with experimental data. Suitable models must be able to show all typical characteristics of the CFB combustion: the load change duration/behavior, the combustion chemistry, the hydrodynamic conditions (particle distribution, temperature development), and the heat transfer. The present study presents a sophisticated 1.5D-model of a CFB combustor based on the core-annulus approach for the CFB furnace. The model is validated with detailed experimental data from CFB combustion of Polish lignite in a $1 \mathrm{MW}_{\text {th }}$ pilot plant under dynamic conditions.

The novelty of the paper is concluded as follows:

1. A series of load changes are carried out in a pilot-scale CFB combustor, representing a typical operation during fluctuating electricity generation by renewables. This involves rapid load cycles in positive and negative direction before stationary states are reached. The effects of ascending and descending load cycles on the temperature and pressure in the furnace are discussed in each case. To the author's best knowledge, this is done for the first time with such detailed experimental data.

2. The study presents a highly sophisticated CFB combustor model based on the core-annulus approach for the furnace. The literature is given an insight into the modeling process of this type of process model and future research in this field will be accelerated.

3. The agreement between experiment and simulation is very good and the model is suitable for the deeper investigation of fuel and load ramp flexibility in future work.

4. Weaknesses of the model are identified which can be used in future research to further increase the agreement between experiment and simulation.

\section{Experimental}

The following chapter describes the test facility including the pilot plant, the measurement equipment, and the cooling system. Afterward, the experimental procedure is presented with the most important boundary conditions of the experiment. 


\subsection{Pilot Plant Description}

Experiments were carried out in a $1 \mathrm{MW}_{\text {th }}$ CFB furnace for the combustion of low-rank Polish lignite. The flow diagram of the CFB reactor (CFB600) and its subsystems is shown in Figure 1. The main components of the facility are the air-supply system (primary air, secondary air, and burner air), the reactor with a hot-loop circulation (cyclone and loop seal), the solid handling systems (solid feeding and ash extraction), the cooling system and the flue gas line (heat exchanger, bag filter, induced-draft fan).

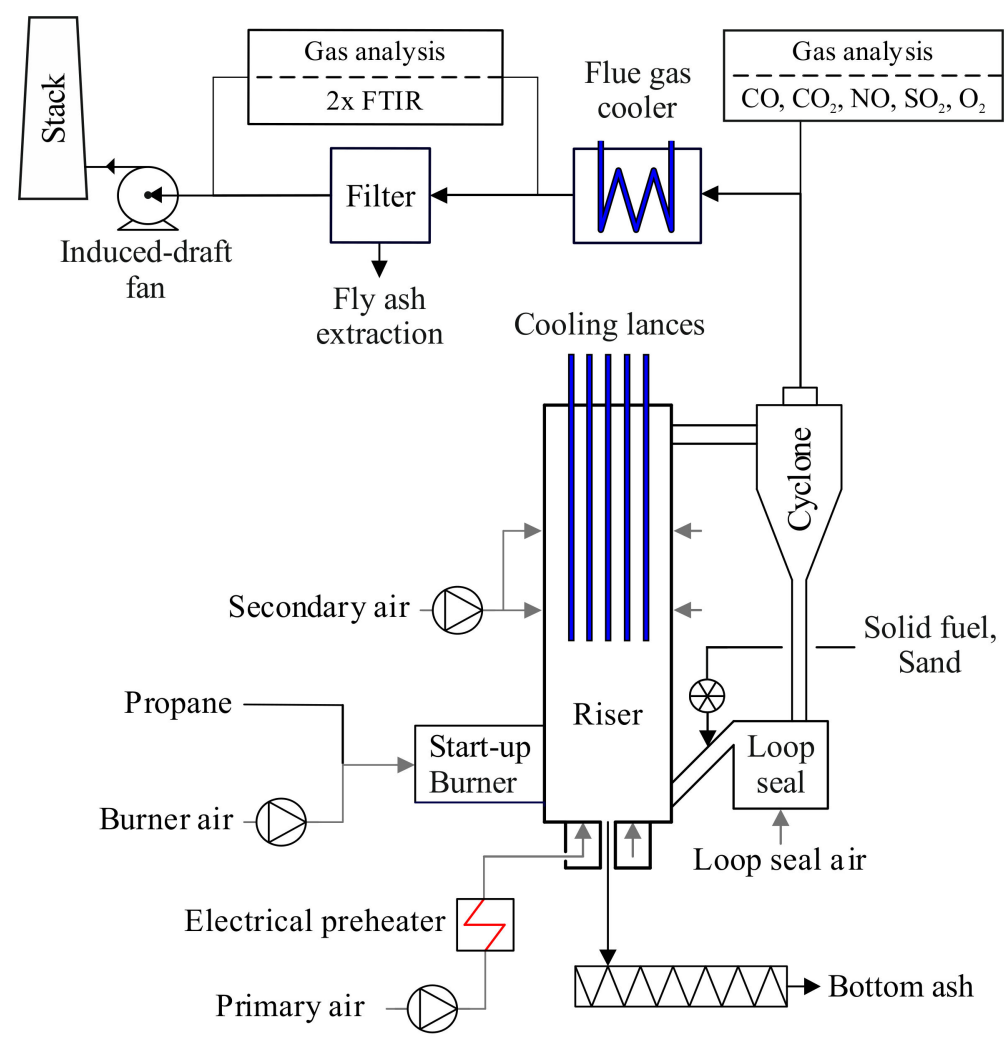

Figure 1. Simplified flow diagram of the $1 \mathrm{MW}_{\text {th }}$ pilot plant.

\subsubsection{CFB Furnace and Auxiliary Systems}

The furnace of the CFB600 reactor includes the riser and a hot-loop circulation for the recirculation of solids. The reactor itself has an inner diameter of $0.59 \mathrm{~m}$ and a total height of $8.6 \mathrm{~m}$. It is fully refractory-lined and the outer diameter of the refractory is $1.3 \mathrm{~m}$. Table 1 shows selected design parameters of the furnace. See Figure A1 in the Appendix A for a detailed geometry of the CFB combustor.

Solids that leave the riser, enter a cyclone, which separates them from the flue gas. The flue gas and fly ash enter the flue gas line with a small amount of fly ash. The main portion of the solids is recirculated to the furnace by a standpipe and a loop seal. Thereby, the residence time of char particles inside the furnace increases and the burn-out of the fuel improves. Air is injected into the loop seal at $25{ }^{\circ} \mathrm{C}$ via two nozzles to maintain fluidization of particles and to ensure a continuous recirculation. Besides the purpose of hot solid recirculation, the loop seal also provides pressure sealing between riser and standpipe/cyclone. Five water-cooled lances can be immersed vertically into the reactor at varying depth to control the combustion temperature. 
Table 1. Design parameters of the furnace.

\begin{tabular}{lc}
\hline \multicolumn{1}{c}{ Parameter } & Value \\
\hline Furnace inner diameter [m] & 0.59 \\
\hline Furnace outer diameter [m] & 1.3 \\
\hline Furnace height [m] & 8.6 \\
\hline Furnace free volume $\left[\mathrm{m}^{3}\right]$ & 2.37 \\
\hline Height: Solids inlet (fuel, sand) [m] & 0.481 \\
\hline Height: Secondary air inlet 1 [m] & 2.74 \\
\hline Height: Secondary air inlet 2 [m] & 6.0 \\
\hline Height: Loop seal solid recirculation to riser [m] & 0.481 \\
\hline Height: Burner air inlet [m] & 0.699 \\
\hline Height: Temperature sensors [m] & $0.25,1.12,1.55,2.38,6.25,8.21$ \\
\hline Height: Pressure sensors [m] & $0.11,0.22,0.4,0.58,0.91,1.1,2.07,3.42,7.31,8.03$ \\
\hline
\end{tabular}

The combustion air is injected into the furnace at several locations and heights. The primary air is entering the furnace via a nozzle grid at the bottom of the riser. It is electrically preheated to around $300{ }^{\circ} \mathrm{C}$ before entering the reactor. A primary air fan controls the mass flow rate to a certain set point. Secondary air enters the riser at two different heights $(2.74 \mathrm{~m}$ and $6.0 \mathrm{~m})$ with two oppositely arranged nozzles at each elevation. A fan provides the desired mass flow of secondary air. The third major portion of the air is injected via the start-up burner at a height of $0.70 \mathrm{~m}$. During start-up, this burner is fired with propane. During the tests, the air is supplied here to prevent backflow of particles and cool the burner components. The secondary and the burner air are not preheated and enter the furnace at an ambient temperature of around $25^{\circ} \mathrm{C}$.

A screw conveyor feeding system feeds solid fuel to a rotary valve, which is located above the return leg. The return leg connects the loop seal and riser. Thereby, the fuel is rapidly flowing to the bed of the furnace at a height of $0.48 \mathrm{~m}$. The rotary valve guarantees pressure sealing between the reactor and the feeding systems. Another screw conveyor feeding system feeds sand to the same rotary valve. A water-cooled conveying screw extracts bed material via a downpipe in the middle of the nozzle grid. The particles are extracted batch-wise to keep the inventory in a suitable range. The target is to keep the bed pressure between 50 and 60 mbar.

The flue gas and fly ash leave the reactor through the cyclone. Afterward, it flows to the flue gas heat exchanger and cools down for further treatment. The heat exchanger is water-cooled and is arranged in two vertical paths. After cooling down, the flue gas is separated from the fly ash in a fabric filter. The fly ash is collected in a hopper and transported to a barrel by a rotary valve. A downstream induced-draft (ID) fan ensures a constant pressure of around 1 mbar below ambient pressure after the cyclone. After leaving the ID fan, the flue gas leaves the system through the stack at a temperature of $130-150{ }^{\circ} \mathrm{C}$.

\subsubsection{Measurement Equipment}

The pilot plant is equipped with measurement equipment for temperatures, pressures, mass flow rates, and flue gas composition at several measurement locations. The temperatures and pressures are measured inside the riser, the hot loop circulation, the flue gas path, and the peripheral systems. Orifice plates and venturi nozzles measure the flow rate of the combustion air and the flue gas. The mass flow rate of solids is measured either by weight decrease (the continuous measurement of fuel and sand) or weight increase (the discontinuous measurement of bottom ash and fly ash). Solid samples are taken from these positions to analyze the chemical composition and the physical/mechanical properties of the solids. The flue gas composition is measured at three locations. The volumetric concentration 
(dry state) of oxygen, carbon dioxide, carbon monoxide, nitrogen oxide, and sulfur dioxide is measured after the cyclone with a paramagnetic sensor for $\mathrm{O}_{2}$ and an NDIR (nondispersive infrared) sensor for the other gases. Before and after the fabric filter, the gas composition is measured with two FTIR (Fourier-transform infrared spectroscopy) measurement devices, which are additionally equipped with oxygen sensors. Besides the main gas components $\left(\mathrm{O}_{2}, \mathrm{CO}_{2}, \mathrm{H}_{2} \mathrm{O}\right)$, the concentration of trace gases $\left(\mathrm{HCl}, \mathrm{NO}_{\mathrm{x}}, \mathrm{SO}_{2}, \mathrm{NO}, \mathrm{CH}_{4}, \mathrm{CO}\right)$ can be measured with these FTIRs.

\subsubsection{Cooling System}

Figure 2 shows a simplified scheme of the cold side of the cooling system. Heat is absorbed from the gas-side by two different subsystems. Five water-cooled lances reduce the temperature in the furnace. The lances can be moved vertically into the reactor at varying depth. The immersion depth was fixed during the experiment also at part load (two lances at $4.5 \mathrm{~m}$, three lances at $6.5 \mathrm{~m}$ immersion depth). The cooling lances are manufactured with a double-tube design. Water is flowing down through the inner tube and flowing up through the outer tube of the lances. The second cooling subsystem is located downstream of the cyclone, where the flue gas is cooled down in a two-path heat exchanger. In the first path, the flue gas streams downwards via a tube bundle heat exchanger. It is then redirected upwards via a second tube bundle heat exchanger. The walls of both paths are designed as membrane wall heat exchangers. The mass flow rate of water is measured before and after the cooling lances and after the flue gas cooler. The water temperature is measured before and after each lance. The mixing temperature after the lances is measured and the temperatures before and after each path of the flue gas cooler are measured. The hot water is cooled down in an air re-cooling system to $110^{\circ} \mathrm{C}$ before it re-enters the cooling paths. The cooling system operates at $8-16$ bar and the cooling liquid is always in a liquid state (no steam generation). During the experiment, the inlet temperatures and the mass flow rates of each cooling line are fixed. Thereby, the transferred heat from the gas side to waterside can be determined by the temperature difference of the water between the inlet and outlet of the cooling subsystems. Heat losses in the subsystems are unavoidable in the pilot plant. The heat transfer calculation is therefore subject to uncertainties. The design parameters of the cooling lances and the flue gas cooler are shown in Table 2. 


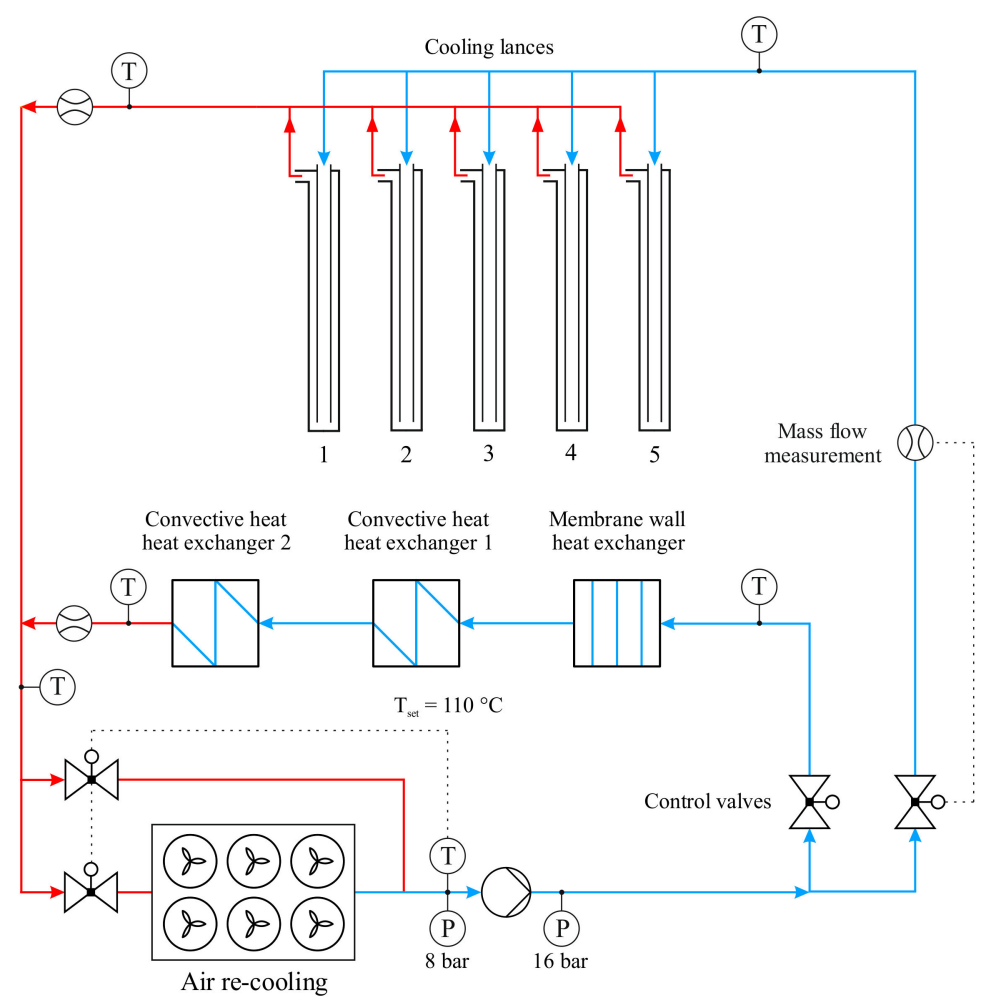

Figure 2. Simplified flow diagram of the cooling system (waterside).

Table 2. Design parameters of the cooling lances and the flue gas cooler.

\begin{tabular}{clc}
\hline Cooling Subsystem & \multicolumn{1}{c}{ Parameter } & Value \\
\hline \multirow{5}{*}{ Cooling lances } & Number of lances [-] & 5 \\
\cline { 2 - 3 } & Maximum immersion depth [m] & \multicolumn{1}{c}{8} \\
\cline { 2 - 3 } & Inner diameter of inner tube [mm] & 33.6 \\
\cline { 2 - 3 } & Outer diameter of inner tube [mm] & 42.4 \\
\cline { 2 - 3 } & Inner diameter of outer tube [mm] & 53.1 \\
\cline { 2 - 3 } & Outer diameter of outer tube [mm] & 60.3 \\
\hline \multirow{3}{*}{ Flue gas cooler } & Tube bundle pipe outer diameter [mm] & 31.8 \\
\cline { 2 - 3 } & Tube bundle pipe inner diameter [mm] & 25.4 \\
\cline { 2 - 3 } & Tube bundle pipe length [m] & 0.5 \\
\cline { 2 - 3 } & Number of tube bundle pipes [-] & 192 \\
\hline
\end{tabular}

\subsection{Experimental Conditions and Procedure}

Low-rank polish-lignite was combusted in the experiments in the pilot CFB furnace. The lignite has a lower heating value of $11.4 \mathrm{MJ} / \mathrm{kg}$ and a moisture content of around $49 \%$. The sand was fed to the furnace to improve the fluidization properties and keep the bed particle size in a suitable range for CFB combustion. The proximate and ultimate analyses of the raw and dried lignite are shown in Table 3, while the properties of the sand are shown in Table 4 . The average particle size of the sand particles is $200 \mu \mathrm{m}$. 
Table 3. Analyses of the polish lignite (ultimate, proximate, others).

\begin{tabular}{lcc}
\hline \multicolumn{1}{c}{ Property } & Fuel Analysis & \\
\hline $\mathrm{C}[\mathrm{wt}-\%]$ & As Received & Dry \\
\hline $\mathrm{H}[\mathrm{wt}-\%]$ & 29.31 & 57.70 \\
\hline $\mathrm{O}[\mathrm{wt}-\%]$ & 2.16 & 20.10 \\
\hline $\mathrm{N}$ [wt-\%] & 10.21 & 0.72 \\
\hline $\mathrm{S}[\mathrm{wt}-\%]$ & 0.37 & 1.65 \\
\hline Moisture [wt-\%] & 0.84 & 0.00 \\
\hline Ash [wt-\%] & 49.20 & 15.55 \\
\hline Fixed C [wt-\%] & 7.90 & 36.24 \\
\hline Volatiles [wt-\%] & 18.41 & 48.21 \\
\hline Lower heating value [MJ/kg] & 24.49 & 22.4 \\
\hline CaO in ash [wt-\%] & 11.4 & 16.70 \\
\hline $\mathrm{D}(10)[\mathrm{mm}]$ & 16.70 & - \\
\hline $\mathrm{D}(50)[\mathrm{mm}]$ & 0.797 & - \\
\hline $\mathrm{D}(90)[\mathrm{mm}]$ & 8.656 & - \\
\hline Bulk density [kg/m $\left.{ }^{3}\right]$ & 13.369 & - \\
\hline
\end{tabular}

Table 4. Properties of sand.

\begin{tabular}{lc}
\multicolumn{1}{c}{ Parameter } & Value \\
\hline $\mathrm{D}(10)[\mathrm{mm}]$ & 0.138 \\
\hline $\mathrm{D}(50)[\mathrm{mm}]$ & 0.204 \\
\hline $\mathrm{D}(90)[\mathrm{mm}]$ & 0.287 \\
\hline Particle density $\left[\mathrm{kg} / \mathrm{m}^{3}\right]$ & 2650 \\
\hline Specific heat capacity at $800{ }^{\circ} \mathrm{C}[\mathrm{kJ} / \mathrm{kg} \mathrm{K}]$ & 1.37 \\
\hline Heat conductivity coefficient at $800^{\circ} \mathrm{C}[\mathrm{W} / \mathrm{m} \mathrm{K}]$ & 25 \\
\hline
\end{tabular}

To evaluate the long-term steady-state behavior of the fuel, a 57-h test was carried out at the beginning of the test series with a thermal load of $845 \mathrm{~kW}_{\mathrm{th}}$. Short-term fluctuations of the fuel mass flow rate and composition are compensated in such a long period, making this test point very suitable for tuning and validation of process simulations. After the steady-state test, load change tests were carried out to evaluate the dynamic behavior and the hydrodynamic conditions at low loads. Firstly, the load was slowly reduced to $648 \mathrm{~kW}$. After a stabilization time, the load was increased stepwise to $914 \mathrm{~kW}$ and $1032 \mathrm{~kW}$. The thermal load depends on the speed of the conveying screw of the fuel, but also on changing properties of the fuel such as bulk density, moisture content, particle size, and chemical composition. To keep the excess-air factor nearly constant, the air mass flow rates were increased to the desired set point and only the fuel mass flow rate was controlled to keep an oxygen excess of around 4-6 Vol-\% $\%_{\text {wet. }}$. With the same approach, two load decreasing steps from $1032 \mathrm{~kW}$ to $921 \mathrm{~kW}$ and $699 \mathrm{~kW}$ were performed. After each load change, the pilot was operated in the same conditions for at least $50 \mathrm{~min}$ before the next load step was carried out. The large thermal inertia of the bed material acts as a buffer after a load change. Therefore, the stabilization time of $\sim 50 \mathrm{~min}$ is not long enough to achieve steady-state conditions for each part-load test. However, the fluctuating behavior of wind and solar power requires quick and flexible load changes by power plants. In the energy market nowadays, it is necessary to perform load changes, when steady-state conditions are not achieved. 
The target of the experiments was to represent this behavior. Table 5 presents the conditions of the long-term steady-state test and the part-load tests. The experimental approach for the load changes is illustrated in Figure 3. As mentioned, the mass flow of the solid fuel fluctuates strongly, so that the figure only illustrates the average mass flow/setpoint and not the actual one. For the evaluation of the tests, mean values are calculated for the temperature, pressure, and other measured parameters for each part-load test. This evaluation period starts $15 \mathrm{~min}$ after each load change and ends $5 \mathrm{~min}$ before the next load change.

Table 5. Test conditions at steady-state and part-loads.

\begin{tabular}{llcccccc}
\hline \multicolumn{1}{c}{ Property } & Unit & $\begin{array}{c}\text { Tuning Point } \\
\mathbf{8 2 \% \text { Load }}\end{array}$ & $\begin{array}{c}\mathbf{6 3 \%} \\
\text { Load }\end{array}$ & $\begin{array}{c}\mathbf{8 8 \%} \\
\text { Load }\end{array}$ & $\begin{array}{c}\mathbf{1 0 0 \%} \\
\text { Load }\end{array}$ & $\begin{array}{c}\mathbf{8 9 \%} \\
\text { Load }\end{array}$ & $\begin{array}{c}\mathbf{6 8 \%} \\
\text { Load }\end{array}$ \\
\hline Primary air mass flow rate & $\mathrm{kg} / \mathrm{h}$ & 690.9 & 426.2 & 568.3 & 710.2 & 568.0 & 425.7 \\
\hline Secondary air mass flow rate & $\mathrm{kg} / \mathrm{h}$ & 615.7 & 347.2 & 490.2 & 633.2 & 490.0 & 346.8 \\
\hline Burner air mass flow rate & $\mathrm{kg} / \mathrm{h}$ & 84.3 & 84.7 & 85.0 & 84.2 & 84.1 & 84.1 \\
\hline Loop seal air mass flow rate & $\mathrm{kg} / \mathrm{h}$ & 30.8 & 39.1 & 39.1 & 37.2 & 37.3 & 37.3 \\
\hline Solid fuel mass flow rate & $\mathrm{kg} / \mathrm{h}$ & 266.8 & 202.2 & 286.2 & 326.5 & 289.8 & 219.1 \\
\hline Sand mass flow rate & $\mathrm{kg} / \mathrm{h}$ & 10.6 & 5.2 & 5.2 & 6.3 & 5.7 & 6.2 \\
\hline Excess-air factor & $\mathrm{mol} / \mathrm{mol}$ & 1.40 & 1.27 & 1.21 & 1.25 & 1.21 & 1.19 \\
\hline
\end{tabular}

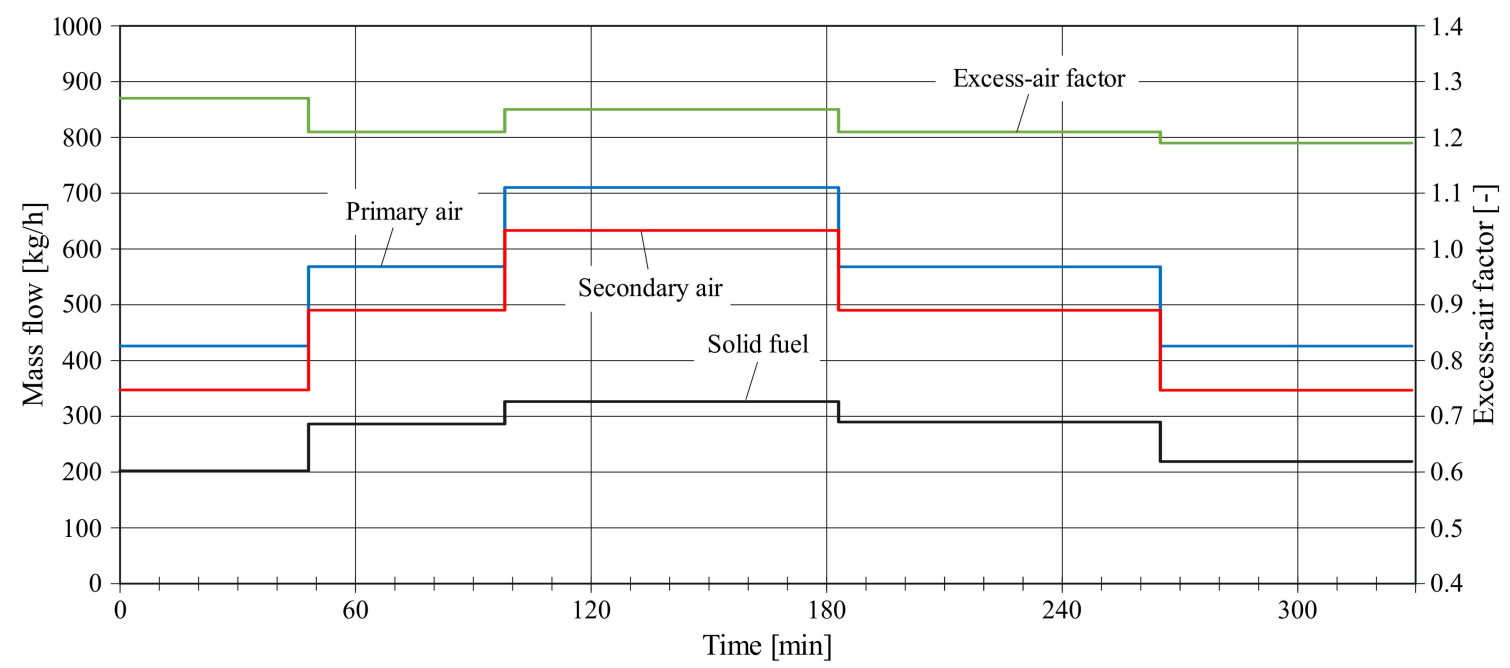

Figure 3. Schematic presentation of test conditions during part-load tests.

Part load conditions are part of the investigation in this paper. At lower loads, the velocity in the furnace decreases. To estimate the state of fluidization in the fluidized bed, it is helpful to compare the present velocity with the minimum fluidization velocity and the transition velocity. These two velocities can be calculated using various formulas. With the help of Grace et al. [23] $u_{m f}$ is estimated to $0.015 \mathrm{~m} / \mathrm{s}$ and $u_{s e}$ is estimated to $6.0 \mathrm{~m} / \mathrm{s}$. The velocity in the furnace depends on the flue gas flow rate, but it also depends on the position, as gaseous components are released along the reactor height and secondary air injection increases the gas flow rate. However, in this study, the velocity in the furnace is estimated according to the following equation, while $T_{\text {avg }}$ is the arithmetic mean of the measured reactor temperatures, the index $\mathrm{N}$ means normal conditions $\left(0^{\circ} \mathrm{C}, 1.01325 \mathrm{bar}\right)$, and $\mathrm{A}$ is the reactor cross-section:

$$
v_{\text {avg }}=\frac{\dot{V}_{\text {Flue gas }}}{A_{\text {Reactor }}}=\frac{\dot{V}_{\text {flue gas }, N}}{A_{\text {Reactor }}} \cdot \frac{T_{\text {avg }}+273.15 \mathrm{~K}}{273.15 \mathrm{~K}}
$$




\section{Model Description}

The model of the pilot CFB furnace is created with the software APROS (Advanced Process Simulation). APROS was developed by Fortum and the Technical Research Centre of Finland (VTT) [21,24-28]. Process components such as pumps, fans, heat exchangers, or piping can be selected from a component library of the programme to model the process realistically. The components are connected via mass flow and energy equations. Data of the process components can be inserted at a high level of detail. Geometries, material properties, and characteristic curves of electrical machines can be inserted into the model. APROS is often used in literature for the modeling of thermal processes, especially thermal power plants, such as pulverized-coal fired power plants [20,29-31], municipal waste incinerators [32], circulating fluidized beds [21,33], concentrated solar power plants [34-36], and nuclear power plants $[37,38]$.

The test facility in Darmstadt is modeled in detail with APROS, using the design data of the pilot plant. The subsystems fluidized bed combustor, air-supply, cooling system, flue gas path, and several boundary conditions for the simulation are modeled in individual nets with high detail. Where no suitable standard components are provided by APROS library (e.g., air preheater, and bag-house filter), the components are implemented with an in-house code. The homogeneous flow model describes the fluid properties and behavior in the combustion air lines, the flue gas path and the waterside of the cooling system. After the model was built, it was tuned with the long-term steady-state experiment at $82 \%$ thermal load. The test duration for this test point was $57 \mathrm{~h}$, so the experimental data is considered to be very reliable. According to the experimental test schedule, the load was decreased afterward to $63 \%$. Then, the load increasing (63-88-100\%) and load decreasing steps (100-89-68\%) were performed according to the test procedure described in Section 2.2. After tuning, the model was validated with the experimental data of the transient operation. Pressures, and temperatures inside and after the furnace, as well as the flue gas composition, were compared to the measurement data for validation.

\subsection{APROS Model}

The core of the APROS model of the pilot plant is the circulating fluidized bed reactor. Figure 4 shows the process diagram of the net of the CFB furnace including air supply, solid handling, cooling lances, insulation and the solid recirculation system. The core of the model is the fluidized bed module of the APROS simulation software. It is based on a $1.5 \mathrm{D}$ core annulus approach. This allows the modelling of a typical circulating fluidized bed flow pattern, in which the particles flow upwards in the core region and downwards in the annulus near to the wall. The fluidized bed module is separated into 20 calculation nodes. Ten types of materials are considered in the riser (three fluids: air, flue gas, water and seven solids: solid fuel, sand, limestone, calcium sulfate, lime, char, ash). The solid recirculation to the riser (in the experiment by the cyclone, standpipe, and loop seal) is modelled with a solid split block (cyclone) and a heat structure module (standpipe and loop seal). In the experiments, the air is injected into the loop seal to maintain fluidization of the solids. This air mainly flows to the standpipe, heats up, mixes with the flue gas and leaves the reactor through the cyclone. To reproduce this behavior, the loop seal air is mixed with the flue gas after the cyclone at a temperature of $300{ }^{\circ} \mathrm{C}$. The heat that is required to increase the temperature of the air from $25^{\circ} \mathrm{C}$ to $300{ }^{\circ} \mathrm{C}$ is taken into account, by withdrawing exactly this amount of heat from the recirculating solids. Solid fuel is injected to the riser at $0.481 \mathrm{~m}$, while the fuel is separated into three components before injection: water/moisture, lime, and the rest of the fuel (dry fuel without lime). Water is separated from the fuel to avoid numerical instabilities according to the user manual of APROS. Lime is supplied separately to take into account the desulfurization reaction $\left(\mathrm{CaO}+\mathrm{SO}_{2}+1 / 2 \mathrm{O}_{2} \rightarrow \mathrm{CaSO}_{4}\right)$. The individual mass flow rates of the three components are calculated based on the ultimate and proximate analyses of the fuel, see Table 3. 


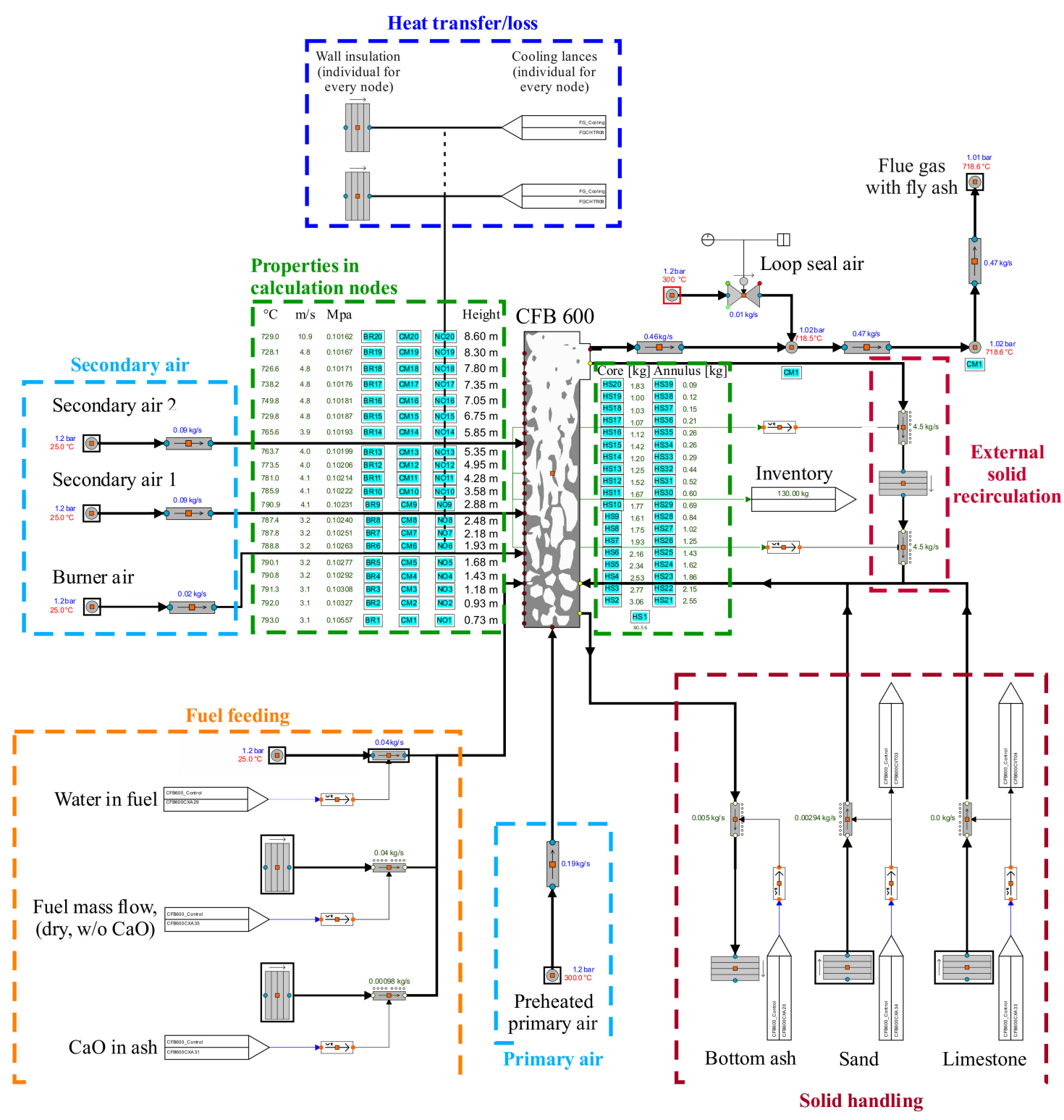

Figure 4. Circulating fluidized bed (CFB) combustor net.

In the model, the mass flow of the bottom ash is calculated by solving the solids mass balance. A major part of the incoming solid fuel is converted to gas by drying, devolatilization, and combustion reactions. Contrary, a small part of the gas is converted back to a solid state (e.g., by desulphurization reaction). After the chemical reactions, the solid materials ash, sand, lime, calcium sulfate, and unburned carbon leave the reactor either as fly ash or as bottom ash. The bottom ash mass flow is adjusted in such a way to maintain a constant inventory of a pre-defined set point of $130 \mathrm{~kg}$.

The air is supplied to the reactor by three main lines: primary air, secondary air (injection at two different heights), and burner air. The air supply is modeled in a separate net, which is not shown here. The air streams enter the riser at the same height and at the same temperature as in the experiment. The primary air pre-heating is modeled by the implementation of a PI controller that either increases or decreases the heat supply to the air stream to match the temperature set point. Each of the combustion air streams is modeled by a fan, which speed is controlled by a PI controller to supply the specified mass flow rate (with the setpoint coming from the experimental data). The piping of the air supply is modeled with the APROS module "pipe". The geometrical and material data for this piping is taken from the pilot plant. 
The flue gas path (from the heat exchanger to stack) is modeled in detail in another net. The flue gas flows to the two-path flue gas cooler, the filter, the ID fan, and the stack. Geometrical and material data for both paths of the heat exchanger and the piping of the flue gas lines are taken from the pilot plant design and implemented in the model. The fabric filter is not presented by a standard APROS library component. Therefore, a pre-defined pressure drop and a thermal mass are used to represent the filter in the APROS model. In the model and the experiment, the speed of the ID fan is controlled by a PI controller to maintain a pressure of around 1 mbar below ambient conditions at the cyclone outlet.

The cooling system is modeled according to the design of the cooling system in the experiment, see Figure 2 and Table 2. However, some components such as the air re-cooling unit are not implemented in the model. Instead, fresh cooling water enters the system with $110^{\circ} \mathrm{C}$ and 11 bar (data taken from the experiment). The cold water is pumped to a distributor pipe before it enters the cooling lances and the flue gas cooler. The mass flow through each cooling subsystem is controlled to a certain set point by control valves, while a speed-controlled pump ensures the overall mass flow. In the model, after leaving the subsystems, the hot water is discarded. Three cooling lances are in contact with the calculation nodes 6-20 (corresponds to $6.5 \mathrm{~m}$ immersion depth) and two lances are in contact with the nodes 11-20 (corresponds to $4.5 \mathrm{~m}$ immersion depth).

\subsection{Materials}

In circulating fluidized beds, the high mass of particles in the bed has a high heat storage capacity. This property of the bed has a large impact during load following operation. Therefore, it is important to implement the heat capacity and the thermal conductivity of the bed materials with high accuracy, if the model is to reflect the experimental data in good agreement. Seven solid materials are present in the riser: sand, solid fuel, char, ash, lime, limestone, and calcium sulfate. Their heat capacity and thermal conductivity highly depend on the temperature, which varies significantly during part load. In the model, this temperature dependency is implemented for many of the solid materials. The thermal conductivity at $800{ }^{\circ} \mathrm{C}$, the temperature-dependent functions for the specific heat capacity and thermal conductivity, and the density of the materials are shown in Tables 6 and 7.

Table 6. Thermal conductivity of solid particles in the riser.

\begin{tabular}{|c|c|c|c|c|c|c|}
\hline \multirow{3}{*}{ Material } & \multicolumn{6}{|c|}{ Thermal Conductivity $[\mathrm{W} / \mathrm{m} / \mathrm{K}]$} \\
\hline & \multirow{2}{*}{$\lambda_{\left(800{ }^{\circ} \mathrm{C}\right)}$} & \multicolumn{5}{|c|}{$\lambda_{(T)}=A+B \cdot T+C \cdot T^{2}+D \cdot T^{3}+E \cdot T^{4}$} \\
\hline & & A & B & $\mathrm{C}$ & D & $\mathbf{E}$ \\
\hline Sand & 25 & $1.04 \times 10^{2}$ & $-2.1 \times 10^{-1}$ & $1.82 \times 10^{-4}$ & $6.87 \times 10^{-8}$ & $9.17 \times 10^{-12}$ \\
\hline Solid fuel & 0.26 & 0.26 & 0 & 0 & 0 & 0 \\
\hline Char & 0.26 & 0.26 & 0 & 0 & 0 & 0 \\
\hline Ash & 1.1 & 0.4 & $1 \times 10^{-3}$ & 0 & 0 & 0 \\
\hline Lime & 1 & 1 & 0 & 0 & 0 & 0 \\
\hline Limestone & 1.03 & 2.3807 & $-4.2 \times 10^{-3}$ & $4 \times 10^{-6}$ & $-2 \times 10^{-9}$ & 0 \\
\hline $\begin{array}{l}\text { Calcium } \\
\text { sulphate }\end{array}$ & 0.17 & 0.17 & 0 & 0 & 0 & 0 \\
\hline
\end{tabular}


Table 7. Density and heat capacity of solid particles in the riser.

\begin{tabular}{|c|c|c|c|c|c|c|}
\hline \multirow[b]{2}{*}{ Material } & \multirow{2}{*}{$\begin{array}{c}\text { Density } \rho \\
{\left[\mathrm{kg} / \mathrm{m}^{3}\right]}\end{array}$} & \multicolumn{5}{|c|}{ Heat Capacity $C_{p(T)}=A+B \cdot T+C \cdot T^{2}+D \cdot T^{3}+E \cdot T^{4}[k J / k g / K]$} \\
\hline & & A & B & $\mathrm{C}$ & D & $\mathrm{E}$ \\
\hline Sand & 2650 & 0.723 & $1.26 \times 10^{-3}$ & $-6.9 \times 10^{-7}$ & $2.67 \times 10^{-10}$ & $-3.8 \times 10^{-14}$ \\
\hline Solid fuel & 1300 & 2.5 & 0 & 0 & 0 & 0 \\
\hline Char & 1350 & 0.739 & $2.09 \times 10^{-3}$ & $-3.6 \times 10^{-6}$ & 0 & 0 \\
\hline Ash & 2400 & 745.6 & 1.041 & $-0.6 \times 10^{-3}$ & 0 & 0 \\
\hline Lime & 3350 & 0.84 & 0 & 0 & 0 & 0 \\
\hline Limestone & 2700 & 0.4091 & $2.1 \times 10^{-3}$ & $-2 \times 10^{-6}$ & $7 \times 10^{-10}$ & 0 \\
\hline $\begin{array}{l}\text { Calcium } \\
\text { sulphate }\end{array}$ & 800 & 1.09 & 0 & 0 & 0 & 0 \\
\hline
\end{tabular}

Tables 8 and 9: The refractory is made of three layers, starting with concrete at the inner layer via calcium silicate in the middle layer and ending with microporous material in the outer layer.

Table 8. Thermal conductivity of furnace insulation.

\begin{tabular}{|c|c|c|c|c|c|}
\hline \multirow{3}{*}{ Material } & \multicolumn{5}{|c|}{ Thermal Conductivity [W/m/K] } \\
\hline & \multirow{2}{*}{$\lambda_{\left(800{ }^{\circ} \mathrm{C}\right)}$} & \multicolumn{4}{|c|}{$\lambda_{(T)}=A+B \cdot T+C \cdot T^{2}+D \cdot T^{3}$} \\
\hline & & A & B & $\mathrm{C}$ & $\mathbf{D}$ \\
\hline $\begin{array}{c}\text { Dense refractory } \\
\text { concrete }\end{array}$ & 1.657 & 3.1 & 0 & -7 & 0 \\
\hline Calcium silicate & 0.2874 & 0.09 & $1 \times 10^{-4}$ & $4 \times 10^{-7}$ & $-2 \times 10^{-10}$ \\
\hline Microporous & 0.05352 & 0.016 & $2 \times 10^{-5}$ & $2 \times 10^{-8}$ & $4 \times 10^{-11}$ \\
\hline
\end{tabular}

Table 9. Density and heat capacity of solid particles in the riser.

\begin{tabular}{cccc}
\hline Material & $\begin{array}{c}\text { Density } \rho \\
{\left[\mathbf{k g} / \mathbf{m}^{3}\right]}\end{array}$ & $\mathbf{A}$ & $\mathbf{H}$ \\
\cline { 3 - 4 } & 2450 & 0.8 & 0 \\
\hline $\begin{array}{c}\text { Dense refractory } \\
\text { concrete }\end{array}$ & 260 & 0.08 & $0.5 \times 10^{-3}$ \\
\hline Calcium silicate & 230 & 1 & 0 \\
\hline Microporous & &
\end{tabular}

\subsection{Procedure of Dynamic Simulations}

The long-term steady-state test run with lignite lasted $57 \mathrm{~h}$ so that short-term fluctuations are compensated and the data is very reliable. Therefore, the test point is suitable to tune the APROS model to the corresponding solid fuel and the bed properties. The objective of the tuning process was to achieve a high agreement between the simulation results of the steady-state test and the experimental data, especially concerning the pressure and temperature profile. Mainly nine parameters were tuned, such as the number of calculation nodes, the heat transfer coefficient calculation method, or the global split coefficient between core and annulus and vice versa. Details of the tuning process and the tuned parameters are presented in Section 4.1.

After the model was tuned, validation of the model was done with the experimental data of the part-load tests. Therefore, no additional parameters were adjusted or tuned and only the boundary conditions were modified. The mass flow of solids (fuel and sand) and the air mass flow was modified with pre-defined setpoints according to the experimental data. Figure 3 shows a graphical visualization 
of the set points in the experiment and the simulation. As in the experiment, the load was increased from $63 \%$ to $88 \%$ to $100 \%$ followed by a load reduction from $100 \%$ to $89 \%$ and $68 \%$. For details regarding the boundary conditions during the part-load simulations, see Table 5 .

\section{Results}

Low-rank lignite was combusted in a $1 \mathrm{MW}_{\text {th }}$ pilot plant to investigate the operational flexibility of CFB combustion. An APROS model was designed and adjusted to reproduce the experimental results. The underlying objective of this work is to create a model, which can predict the behavior of CFB combustion with different fuels and fuel mixtures and at varying load. The data is presented here to provide valuable input for future research in the field of the flexibility of CFB combustion. The first part of this section describes the model tuning process. Additionally, the temperature profile, the pressure profile, and the gas composition of the tuned model are presented and compared to experimental data of the long-term steady-state test. The experimental data is averaged over the complete testing time and the standard deviation is used to illustrate the fluctuations during the test. After the tuning process, the validation process with five test points at part load is presented. The development of the pressure and temperature along the furnace height is presented on average and over time to evaluate the average part-load conditions as well as the dynamic behavior of the boiler. The validation process focusses on the hydrodynamics, the flue gas composition, and the dynamic behavior during load increasing and decreasing conditions.

\subsection{Steady-State Model Tuning}

The model was tuned with the experimental data of the 57-h steady-state test at a load of 845 $\mathrm{kW}_{\text {th }}(82 \%$ load). Various model parameters were adjusted and chosen to meet the pressure profile, the temperature profile, and the gas composition of the experiment. Other parameters were tuned to find the best values for high numerical stability and good agreement with the experimental data. The most relevant parameters are listed in Table 10 with a short description. The riser is separated into 20 nodes. If the 20 nodes were equally distributed over the riser height, each node would have a height of $0.43 \mathrm{~m}$. However, the bottom node of the riser has a height of $0.7 \mathrm{~m}$. The bottom node represents the high-density bed zone. Here, no core-annulus approach is implemented due to the high inventory and the enhanced mixing of particles. For numerical stability, the bottom node must be higher than the bed height, which is calculated by APROS by dividing the mass of solid particles in the bed node by the average density of gas and solid particles in this node and the flow area of the node.

The heat transfer from the riser to the waterside depends on the temperature difference, the surface area, and the heat transfer coefficient. The heat transfer coefficient is calculated using the Mattman-Molerus-Wirth correlation. It takes into account the Archimedes number and the local pressure drop/particle fraction [39]. This correlation is recommended for the prediction of heat transfer in circulating fluidized beds [24].

The mass flow of particles from the core to the annulus and vice versa depends on the radial velocities and the mass of solids in the calculation nodes. Without further tuning, the radial velocities of the solids would be set equal to the axial velocities of the solids in the core/annulus. However, in reality, radial and axial velocities are not equal. To adjust the radial velocities and thereby the mass flow rates of the solids, so-called global split coefficients from the core to the annulus and from the annulus to the core are introduced. These coefficients have values between 0 and 1 . With a value of e.g., 1 , the radial velocity is equal to the axial velocity. With a value of e.g., 0.1 , the radial velocity is ten times smaller than the axial velocity. Thereby, the global split coefficients have a great impact on the upflow/downflow of particles in the core/annulus and largely influence the pressure profile. The global split coefficients were adjusted to adapt the pressure profile according to the measurement data. 
Table 10. Attributes/parameters of the CFB combustor model.

\begin{tabular}{|c|c|c|}
\hline Parameter/Attribute & Description & Selected Value \\
\hline Number of calculation nodes & $\begin{array}{l}\text { The number of calculation nodes } \\
\text { inside the riser. The parameter } \\
\text { impacts numerical stability and } \\
\text { model resolution. }\end{array}$ & 20 [nodes] (Varied from 10-100) \\
\hline Height of bottom node & $\begin{array}{l}\text { The height of the bottommost } \\
\text { node (high-density bed zone). No } \\
\text { core-annulus approach is } \\
\text { implemented for this node. This } \\
\text { height must be higher than the } \\
\text { calculated bed height for } \\
\text { numerical stability. }\end{array}$ & $0.7[\mathrm{~m}]$ (Varied from $0.2-0.8)$ \\
\hline Total mass of particles in the bed & $\begin{array}{l}\text { The mass of particles in the } \\
\text { fluidized bed. The value is } \\
\text { estimated from the pressure drop } \\
\text { in the experiment. }\end{array}$ & $130[\mathrm{~kg}]$ (Varied from $120-140)$ \\
\hline $\begin{array}{l}\text { Convection heat transfer } \\
\text { correlation }\end{array}$ & $\begin{array}{l}\text { The calculation method for the } \\
\text { convective heat transfer coefficient } \\
\text { between particles, gas, and } \\
\text { tubes/walls. The parameter } \\
\text { influences the heat transfer to the } \\
\text { cooling lances/insulation. }\end{array}$ & $\begin{array}{c}\text { Mattman-Molerus-Wirth } \\
\text { correlation (recommended for } \\
\text { CFB) }\end{array}$ \\
\hline Heat transfer coefficient & $\begin{array}{l}\text { The coefficient modifies the heat } \\
\text { transfer coefficient calculated by } \\
\text { the convection heat transfer } \\
\text { correlation. }\end{array}$ & $1.5[-]$ (Varied from $1-5)$ \\
\hline $\begin{array}{l}\text { Global split coefficient from core } \\
\text { to annulus/annulus to core }\end{array}$ & $\begin{array}{l}\text { The coefficient reduces the } \\
\text { calculated particle mass flows } \\
\text { from the core to the annulus and } \\
\text { vice versa. The parameter impacts } \\
\text { the pressure profile. }\end{array}$ & $0.03[-]$ (Varied from 0-1) \\
\hline Interface density & $\begin{array}{l}\text { Defines the solid density on the } \\
\text { interface between the high-density } \\
\text { bed and the freeboard. The } \\
\text { interface density affects the } \\
\text { entrainment/the pressure profile. }\end{array}$ & $30\left[\mathrm{~kg} / \mathrm{m}^{3}\right]$ (Varied from $\left.15-50\right)$ \\
\hline
\end{tabular}

Another large influence on the pressure profile is given by the so-called interface density. The amount of particles that are entrained from the high-density bottom node to the first core node directly depends on the axial solid's velocity and the interface density. The interface density is a theoretical value and can be set freely by the user. It represents the suspension density in the zone between the bed and the freeboard. Therefore, it physically represents the density in the splash zone of the fluidized bed. The density can be estimated from the experimental data by using the pressure drop in this area. From the experimental data, it is reasonable to define the location of the splash zone between the two pressure sensors at $0.58 \mathrm{~m}$ and $2.07 \mathrm{~m}$, where the density of the bed changes from high-density zone to lean zone. In the steady-state case, the calculated splash zone density is $58.2 \mathrm{~kg} / \mathrm{m}^{3}$. However, in the model, a value of $30 \mathrm{~kg} / \mathrm{m}^{3}$ was chosen, as the entrainment was highly overestimated, when using a value of $58.2 \mathrm{~kg} / \mathrm{m}^{3}$.

An average diameter has to be set to account for the particle size of the fluidized bed particles and no particle size distribution is implemented in the model. The average particle size is $0.211 \mathrm{~mm}$, which is the average particle size of the bottom ash sample taken after the test period. To calculate the heat loss through the insulation to the environment, a boundary condition has to be set for the ambient 
temperature outside of the refractory lining. This temperature is set to $25^{\circ} \mathrm{C}$ and is not adjusted during the simulations.

Figure 5 shows the pressure profile along with the furnace height during the long-term steady-state test with $845 \mathrm{~kW}_{\text {th }}$ load. The average velocity according to the description in Section 2.2 is calculated to $4.2 \mathrm{~m} / \mathrm{s}$. In the model, the pressure drop in the freeboard is overestimated indicating that the entrainment is higher in the simulation compared to the experiment. The hydrodynamic conditions influence the chemical reactions, the heat transfer, and the temperature development in the furnace. Further improvements of the model are therefore useful to achieve better agreement in future studies-e.g., the interface density parameter can be set to smaller values. In this work, the interface density is already set 2 times smaller than the density in the splash zone. Therefore, it was chosen not to make the parameter even smaller, to have an appropriate compromise between the accuracy of the model and the physical foundation of the interface density. The agreement between experimental data and simulation is good both in terms of the total pressure drop and the reproduction of the typical CFB pressure profile. The figure also shows the standard errors for the experimental data calculated from the standard deviations in the measurement signals and the uncertainty of the measurement devices.
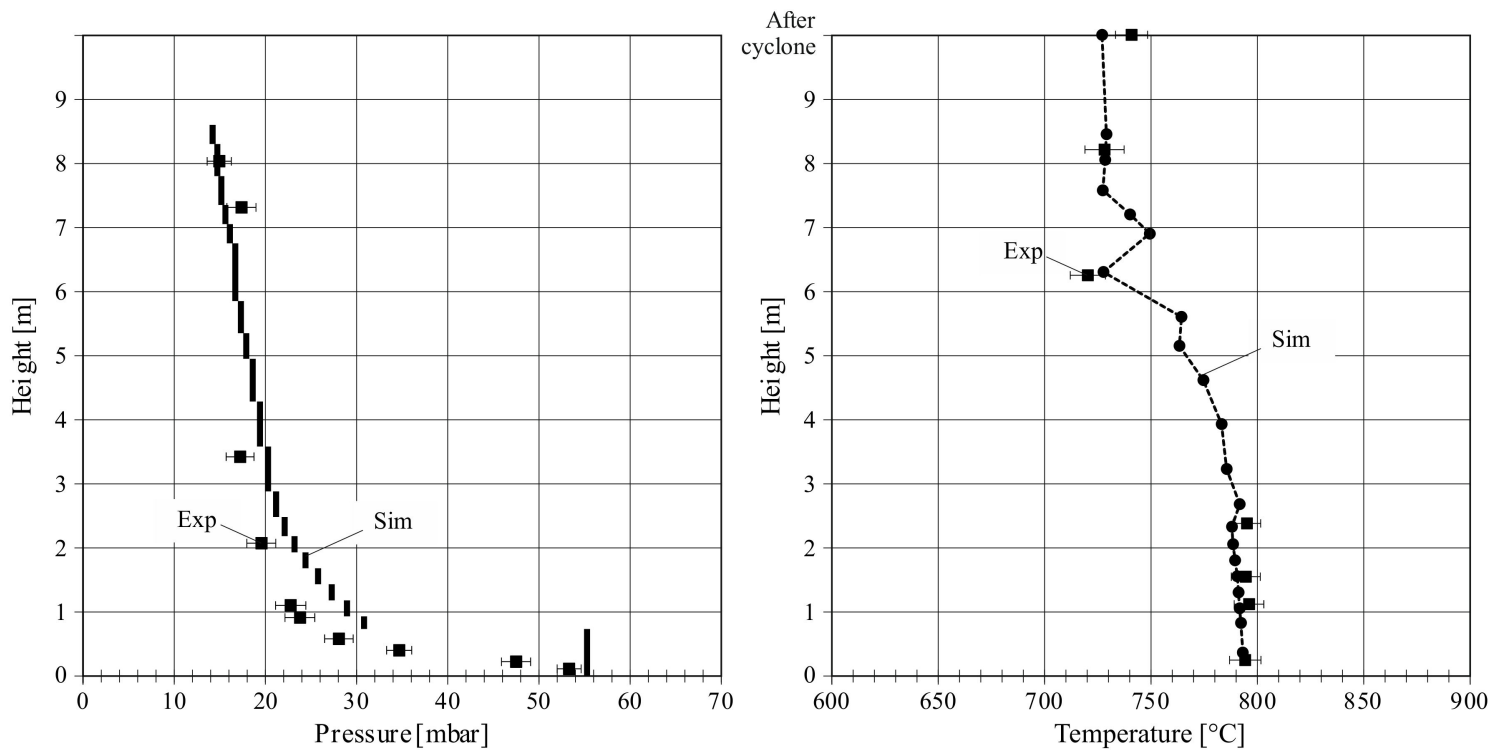

Figure 5. Pressure and temperature along with the reactor height (steady-state test).

The temperature profile is shown on the right in Figure 5. The temperatures in the simulation agree very well with the experiment. In the bed zone, the temperatures are almost constant due to the high level of mixing in the bottom region. At $2.7 \mathrm{~m}$, secondary air is injected. However, the measurement shows decreasing temperatures from 2.4 to $6.3 \mathrm{~m}$ potentially for two reasons. Firstly, the cooling lances and the non-preheated secondary air might compensate for the combustion reactions. Secondly, no measurement is installed between these two locations. Therefore, the temperature might rise above the secondary air injection and it is just not shown by the available experimental data. However, the simulation does not show a temperature increase above $2.7 \mathrm{~m}$ either. In the experiment, the temperature increases above the secondary air injection at $6.0 \mathrm{~m}$ to the last measurement at $8.2 \mathrm{~m}$. In the model, a temperature peak at $7.0 \mathrm{~m}$ is observed, before the temperature decreases again due to the impact of the cooling lances. At $8.2 \mathrm{~m}$, experiment and simulation correspond. In addition to the riser temperatures, the temperature measurement after the cyclone is shown in Figure 5. In the experiment, the temperature increases between riser and cyclone outlet. It is reasonable, that the mixing of secondary air, volatiles, and char is considerably smaller in the experiment, as the penetration depth of the secondary air is not optimized in the pilot. Thereby, the combustion reactions are shifted to the top of the reactor and the cyclone. In the cyclone, the high velocity and the turbulent flow ensure 
a strong mixing leading to the post-combustion of char. In the model, the mixing is very efficient, due to its 1-dimensional nature. Therefore, the combustion reactions are taking place only in the riser and the post-combustion is not reproduced sufficiently.

The flue gas composition is presented in Figure 6. On the left-hand side, the main gas components $\mathrm{O}_{2}, \mathrm{CO}_{2}$, and $\mathrm{H}_{2} \mathrm{O}$ are shown. The standard errors are presented, taking into account the measurement device uncertainty and the standard deviation of the fluctuating measurement signal. The simulation agrees very well with the experiment. Simulation results are always within the standard error of the experiment and the relative deviations are very small. Considering that the composition of the fuel is subject to fluctuations during the experiment, the agreement is considered very high.
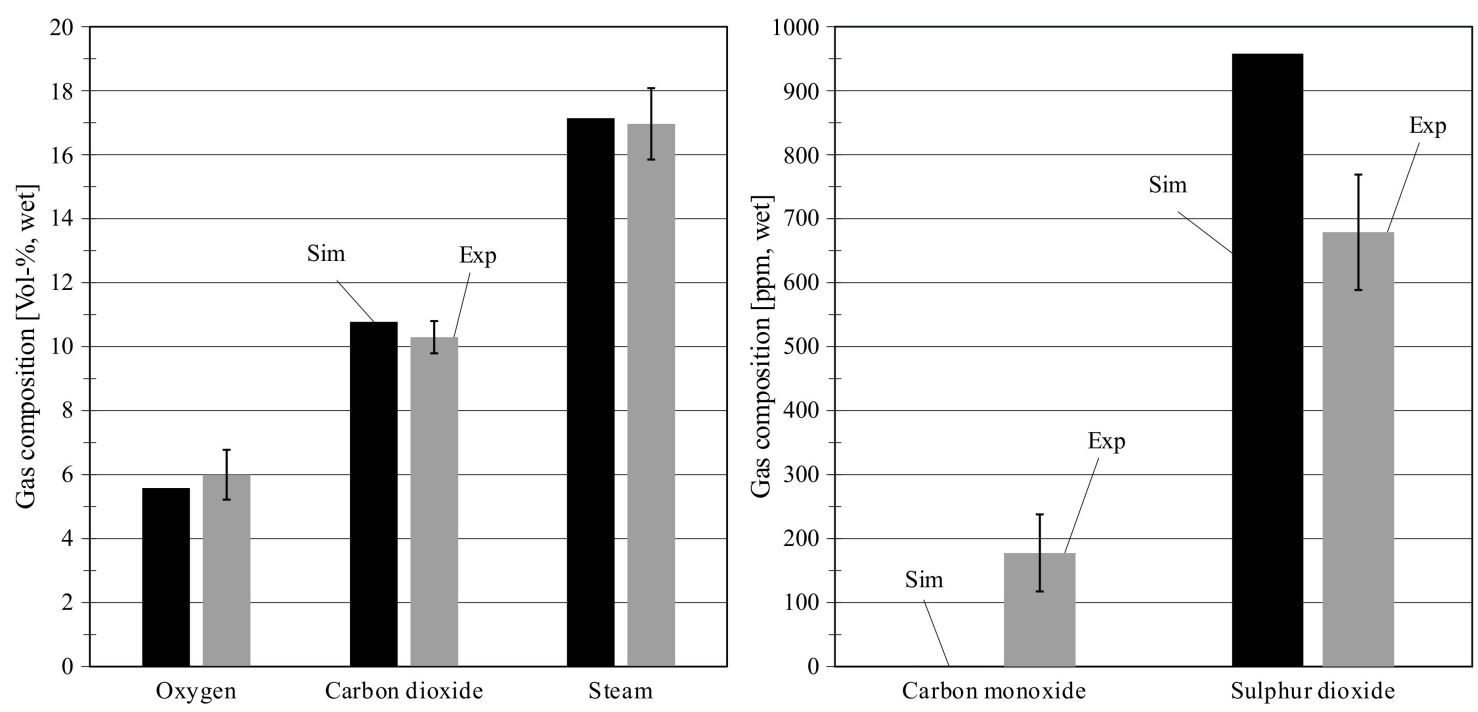

Figure 6. Flue gas composition (steady-state test).

On the right-hand side of Figure 6, the content of the trace gases $\mathrm{CO}$ and $\mathrm{SO}_{2}$ is presented. There is no $\mathrm{CO}$ in the flue gas in the simulation. This supports the findings from the temperature profile of the simulation, where all combustion reactions are completed in the riser. In the experiment, the $\mathrm{CO}$ content is around $200 \mathrm{ppm}_{\mathrm{we}}$, so the combustion reactions are not completed even after the post-combustion in the cyclone. The $\mathrm{SO}_{2}$ content depends on the varying sulfur content in the fuel and on the efficiency of the sulfur capture with calcium oxide from the fuel ash. The sulfur capture in a CFB combustor is a complex process, which depends on many parameters, such as the flue gas composition (locally reducing conditions, water vapour content), the temperature, the residence times and the properties of the CaO-particles (porosity, size, shape) [40-43]. Taking into account all these uncertainties and the fact, that especially the particle properties cannot be defined to this extent in the APROS model, the relative deviation of $41 \%$ between model and experiment is in a comprehensible range. It should be mentioned at this point that no tuning was carried out concerning the desulphurization reactions in the model, besides the definition of the S-content in the fuel and the $\mathrm{CaO}$ content in the fuel ash.

\subsection{Model Validation}

After tuning with the steady-state test, no further tuning or modification of the model took place during the validation process. The model is validated with the measurement data of five test points, with a thermal load from $63 \%$ to $100 \%$. The model validation focusses on the hydrodynamic conditions, the flue gas composition, and the dynamic behavior of the fluidized bed.

\subsubsection{Hydrodynamic Condition in the Furnace}

The hydrodynamic conditions in a CFB furnace depend on the load, the bed material properties, the fuel, the combustion air, the heat exchangers inside the furnace, and other parameters, such as 
the insulation of the furnace. All these parameters are considered in the presented APROS model. The temperature and pressure profiles are a suitable way to validate a process model in terms of the hydrodynamics. Figure 7 shows the pressure and temperature profile of the $100 \%$ load case $(1032 \mathrm{~kW})$ with a calculated average velocity of $4.60 \mathrm{~m} / \mathrm{s}$. The agreement between experiment and simulation is very good for the temperature profile. The bed temperature, as well as the temperature development along the reactor and the temperature at the riser top in the simulation, are within the standard errors of the experimental data. As in the steady-state case, the post-combustion in the cyclone does not happen in the model. Therefore, there is a temperature deviation of about $20 \mathrm{~K}$ between simulation and experiment for the temperature after the cyclone. The pressure profile shows greater deviations than the temperature profile. The overestimation of the pressure drop in the lean zone is similar to the steady-state test. However, the total pressure drop and the slope of the pressure profile in the upper reactor is still in good agreement.
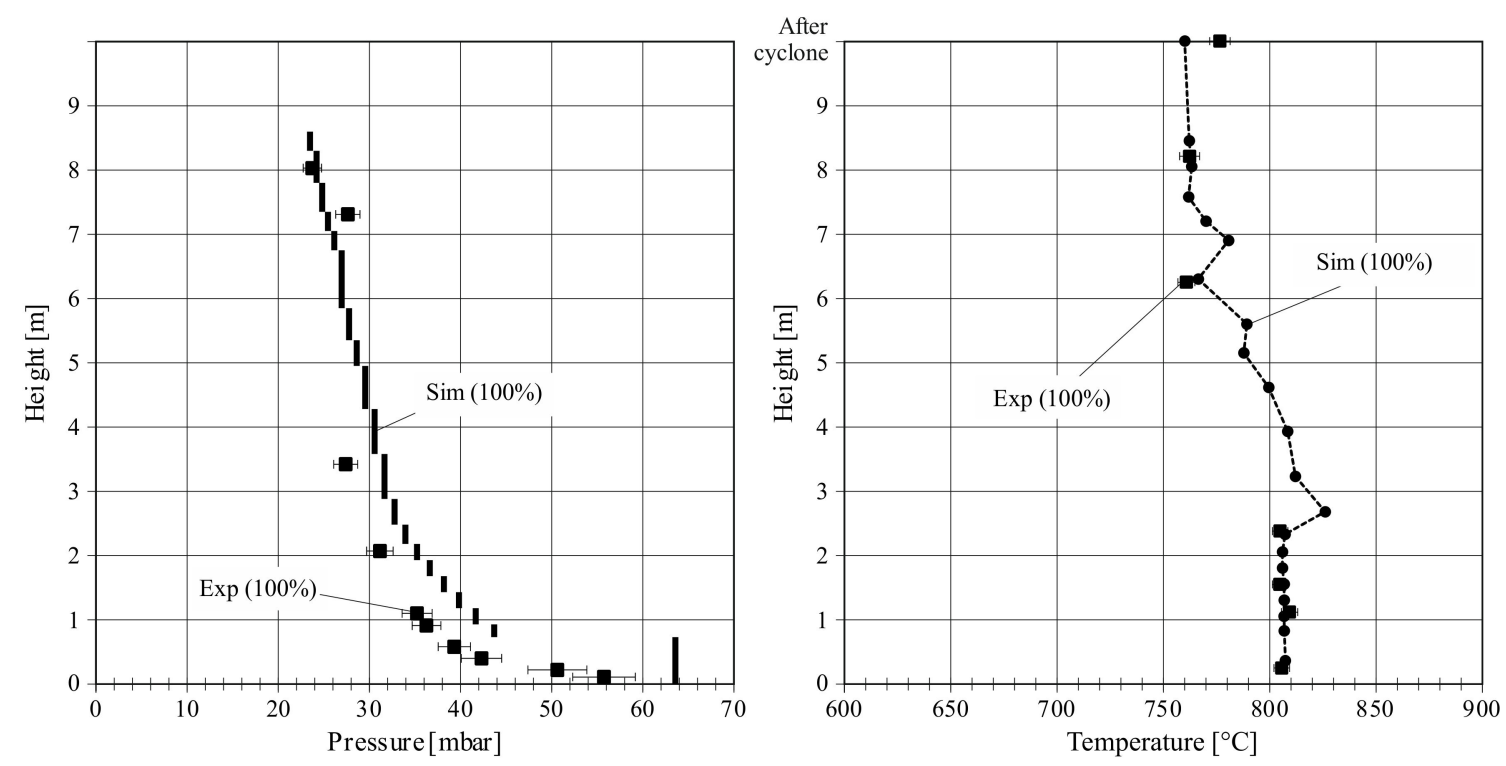

Figure 7. Pressure and temperature along the reactor at high load.

Figure 8 presents the hydrodynamics at medium load $(88 \%, 89 \%)$. The average calculated velocities are $3.70 \mathrm{~m} / \mathrm{s}(88 \%)$ and $3.77 \mathrm{~m} / \mathrm{s}(89 \%)$. The pressure profile is similar for ascending and descending load. The load is slightly higher than in the steady-state tuning test point. However, the velocities are smaller, as the excess air factor is lower in these cases. The pressure drop in the freeboard is overestimated by the model, which could potentially be improved by adjusting the interface density in the model. However, the numerical simulation is capable of predicting the reduced entrainment at decreasing velocities/load cases on the same scale as in the experiment. The agreement between experiment and simulation is good regarding the total pressure drop and the bed density. 

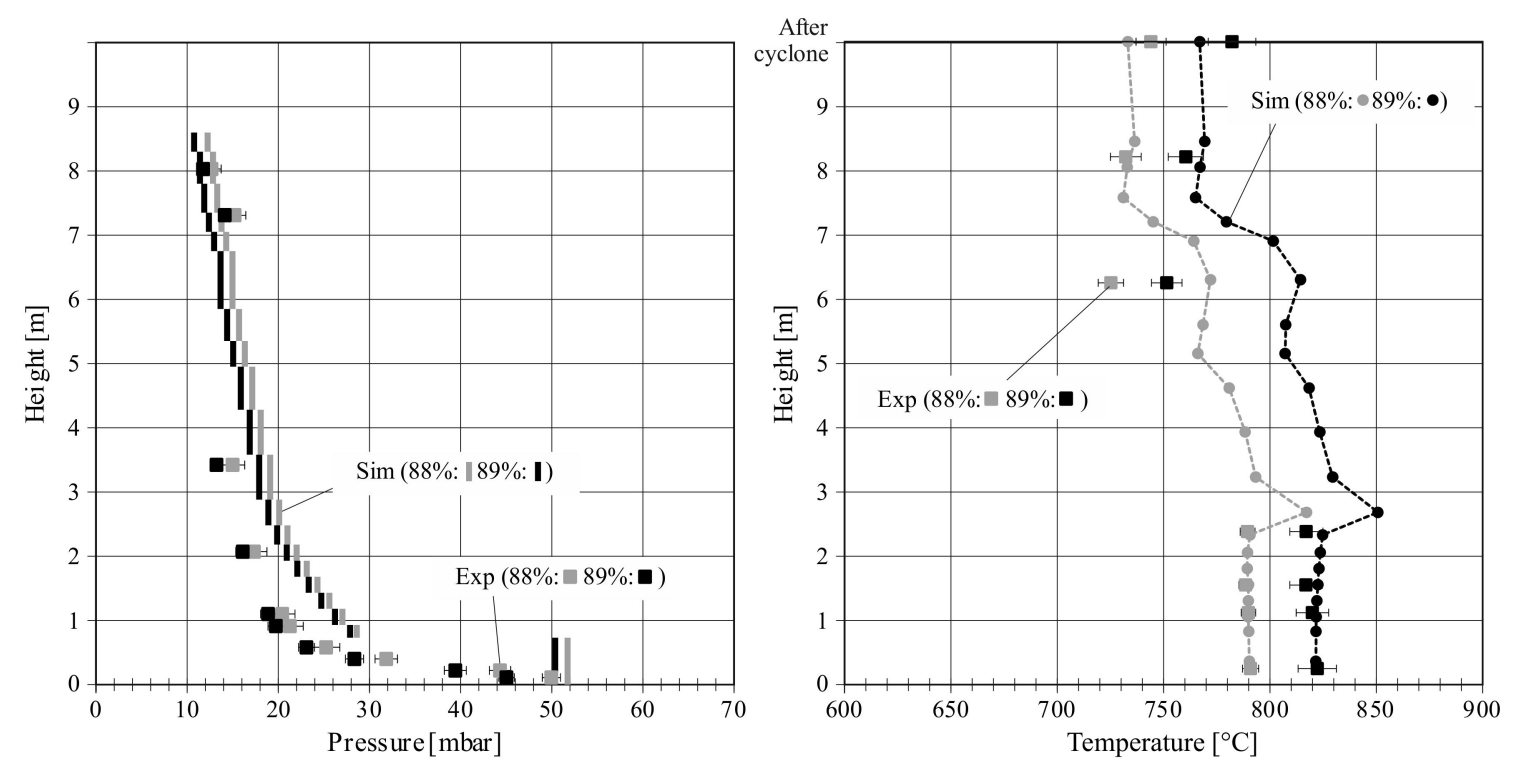

Figure 8. Pressure and temperature along the reactor at medium load.

It is noticeable that the average temperature differs significantly at descending and ascending load changes, despite similar loads. The refractory and the inert bed material play a major role here. A large amount of energy is stored and is then slowly released when the load decreases. Therefore, the temperature level is higher in the case of descending load (89\% load case), as long as steady-state conditions are not achieved. This mechanism is well shown also by the simulation, where this temperature difference is also present. It is necessary to mention here, that the walls of commercial CFB boilers are made of water walls. Therefore, the effect observed here will hardly affect industrial scale boilers.

Despite the different average temperatures, the temperature development along the riser is similar for both medium load tests. Partly, bed temperatures are higher at medium loads compared to high loads. Additionally, the temperature drop along the reactor increases at lower loads (see Figure 7), due to several reasons. Less particles (e.g., char) are entrained from the bed at lower loads/velocities. Thereby the combustion reactions are shifted to the bed zone, which increases the bed temperatures and decreases the temperatures in the upper reactor. When the circulation of particles decreases, fewer particles are cooled by contact with the cooling lances and the surrounding flue gas. This lack of particle-cooling can result in an increased temperature of the solids and thereby an increasing bed temperature. These mechanisms, in combination with the heat stored in the insulation, can lead to an increase in the bed temperature, although the load is reduced. The simulated temperatures match the experiment very well in the high-density bed region and at the reactor top. At $6.3 \mathrm{~m}$ height, there is a larger deviation between model and experiment. Potentially, the heat transfer to the cooling lances is not correctly reproduced at this low load. As already discussed, also the combustion reactions with the secondary air, which is injected at a height of $6.0 \mathrm{~m}$, are completed much faster in the model due to the idealized mixing. This leads to a higher temperature in this area.

The hydrodynamic profiles of the tests with $63 \%$ and $68 \%$ load are illustrated in Figure 9. The calculated velocities are $2.78 \mathrm{~m} / \mathrm{s}(63 \%)$ and $2.88 \mathrm{~m} / \mathrm{s}(68 \%)$. In the experiment, there is only a minor pressure drop along the lean zone of the riser, while the simulation results still show significant entrainment. As discussed before, the model parameter interface density, which largely influences the entrainment, is kept constant for validation purposes. In the experiment, on the other hand, the density in the splash zone is slightly decreasing at lower loads (58.2 mbar at $82 \%$ load and $48.2 \mathrm{mbar}$ at $63 \%$ load). It is therefore reasonable, that the deviation between the pressure profile of the simulation and the experiment may get worse at lower loads. The model gives a good indication of the total pressure loss of the experiment, even if the deviations are greater than at higher load. 

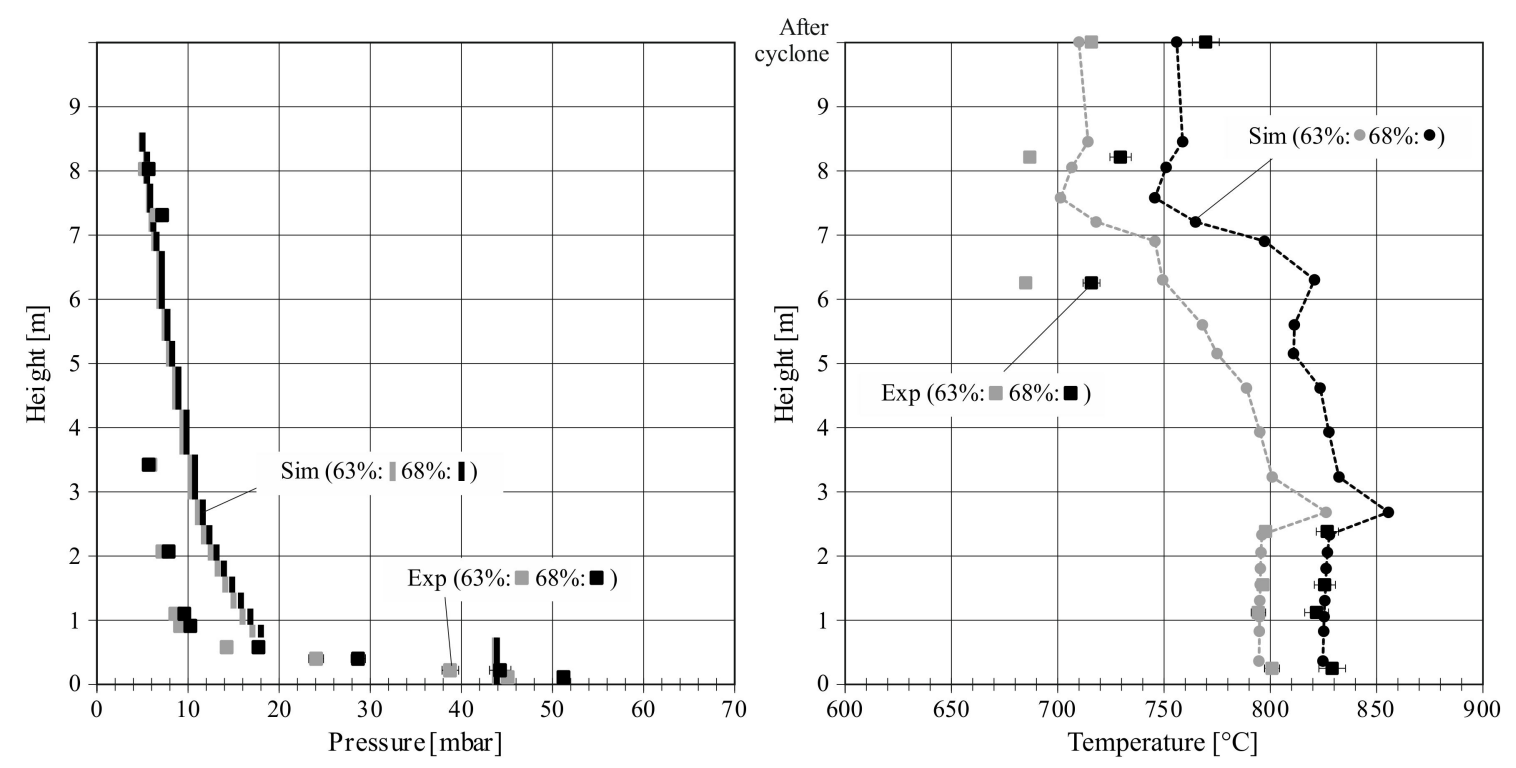

Figure 9. Pressure and temperature along the reactor at low load.

Again, the temperature level is higher for the load reduction test ( $68 \%$ load) compared to the load elevation test $(63 \%)$, which is partly due to the energy stored in the refractory and bed material. However, the load in the latter is also significantly lower, which is also responsible for the higher temperatures. There is an excellent agreement between experiment and simulation for the bed temperatures. The model also shows that the temperature along the reactor decreases much more than it did at higher loads, which matches the experimental data. At the top of the reactor and around $6 \mathrm{~m}$, the deviation between experiment and simulation is higher than at high and medium load, whereby the agreement between experiment and model is much better for the temperature after the cyclone. In the experiment, there is a major level of post-combustion in the cyclone, which is not present in the model due to the reasons discussed before. As the combustion takes place entirely in the riser, the temperatures in the simulation are higher at 6.3 and $8.2 \mathrm{~m}$.

\subsubsection{Flue Gas Composition}

The flue gas composition is measured at several positions in the pilot plant. The FTIR measurement after the flue gas cooler includes all main species including water vapor and many trace gases. This measurement data is compared to the simulation results for the validation of the model. Figure 10 shows the flue gas composition of the part-load tests. In the simulation, the content of carbon dioxide and water vapor is within the standard error of the experiment for all tests. The oxygen content is always at or slightly below the lower limit of the standard error in the experiment. Regarding the fluctuating fuel composition, the model shows an excellent agreement with the experiment. 


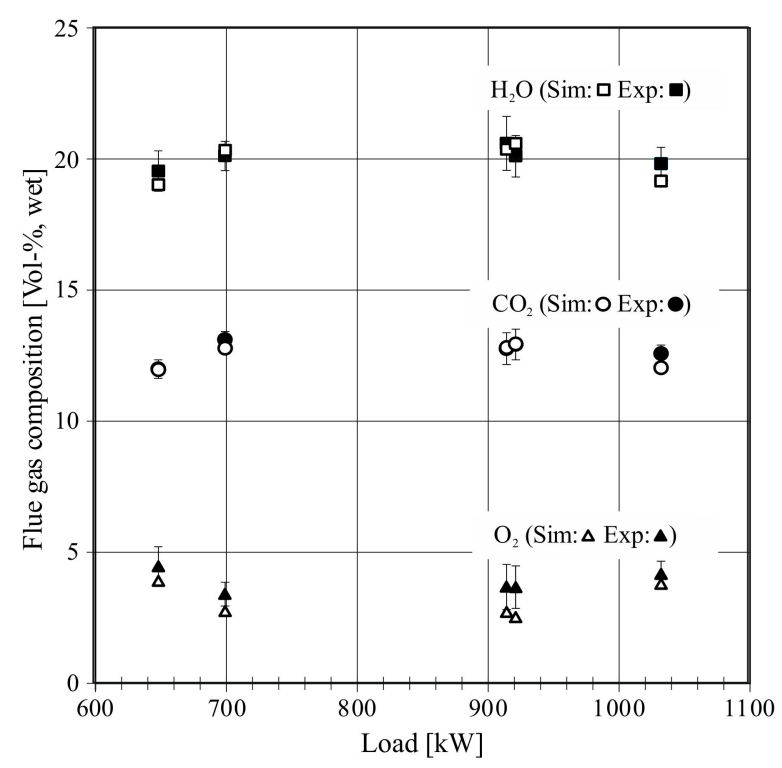

Figure 10. Flue gas composition at part load.

The $\mathrm{CO}$ content in dependency of the average riser temperature is shown in Figure 11. Large fluctuations are present for the $\mathrm{CO}$ content in the experiment. The $\mathrm{CO}$ content tends to decrease with increasing temperature, as high temperatures accelerate the combustion reactions. However, more parameters influence the $\mathrm{CO}$ content, such as the oxygen content and the efficiency of the post-combustion in the cyclone for instance. In the simulation, no carbon monoxide remains in the flue gas and the combustion reactions are completed inside the riser for all tests. As discussed before, the mixing of oxygen and burnable components $(\mathrm{CO}$, char) is modeled as ideal in the 1.5 D APROS model. In the experiment, the mixing depends on several parameters, such as the injection speed of the secondary air and the conditions in the riser.

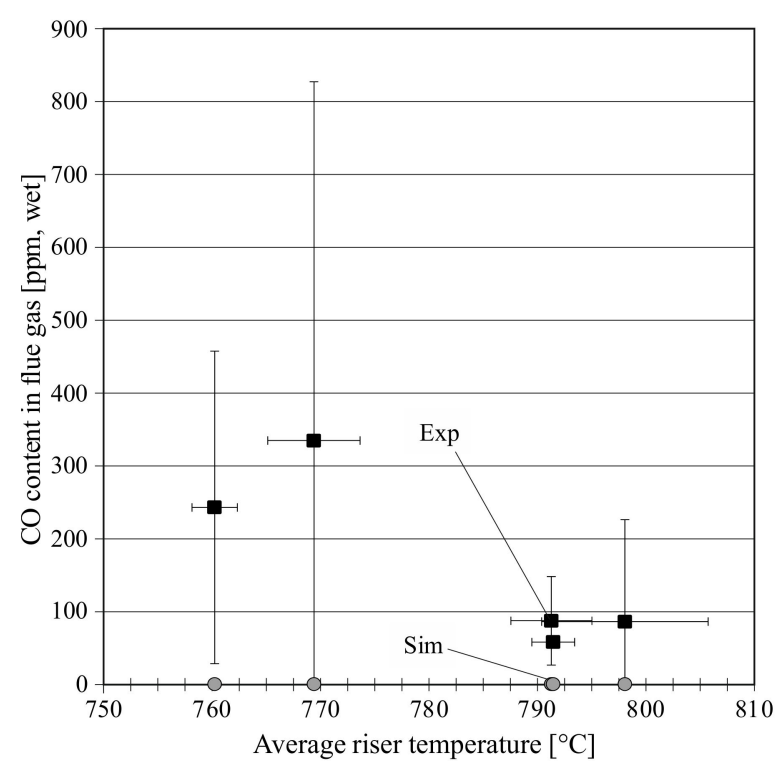

Figure 11. CO content in flue gas for varying riser temperature.

\subsubsection{Dynamic Evaluation}

Besides the evaluation of the part-load tests with mean values for the temperature and pressure, also the dynamic behavior during load change is relevant to validate the process model. In this chapter, 
the dynamic response of the furnace is evaluated and the model prediction of this response is assessed. Figure 12 shows the development of the temperature in the bed and at $8.2 \mathrm{~m}$, the pressure at several heights, and the flue gas composition. The fuel mass flow is varying, due to differences in the fuel properties such as particle size, shape, density, or moisture. In the simulation, these fluctuations are not modeled. This results in fluctuating values for the flue gas composition and the temperatures.
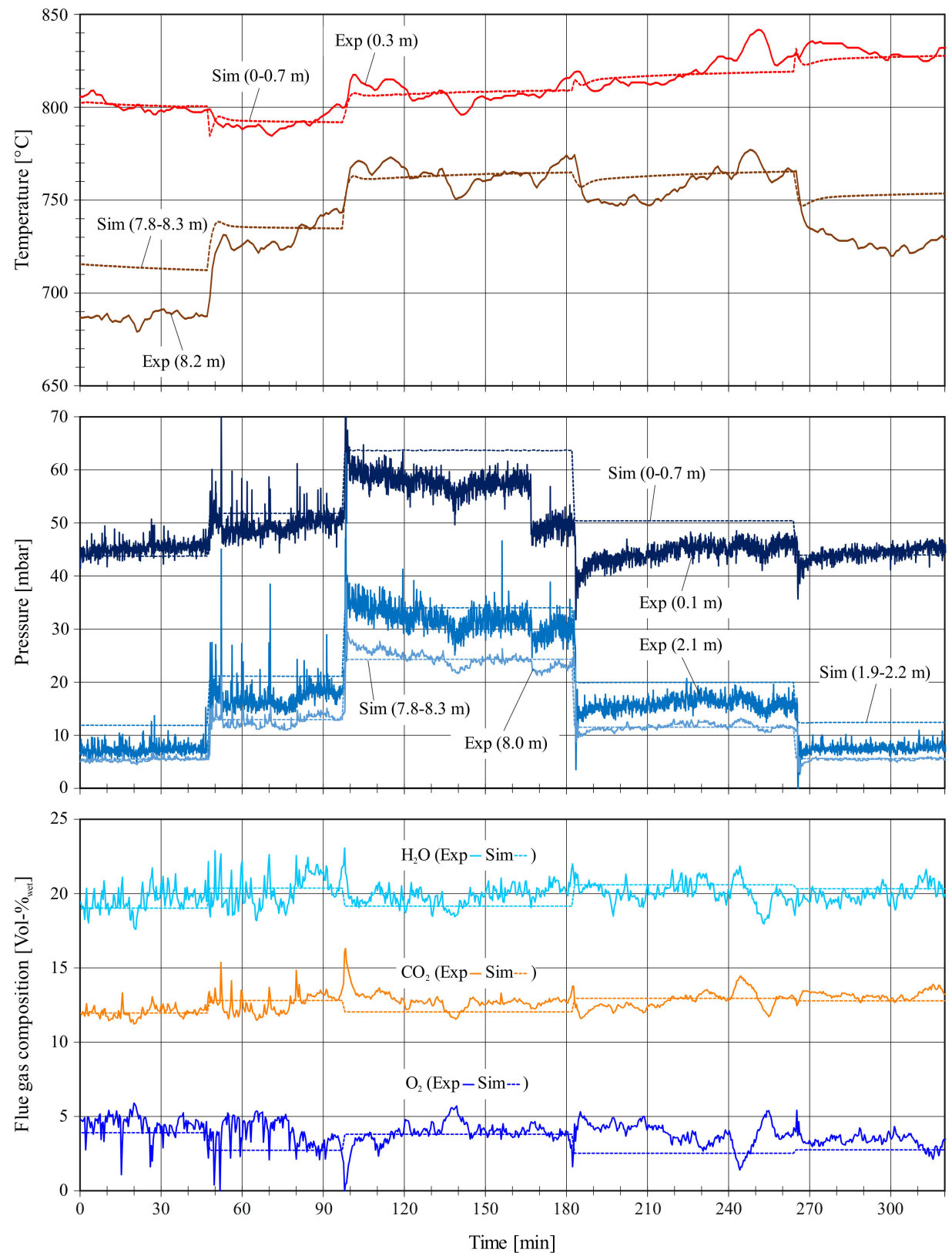

Figure 12. Temperature, pressure, and fuel mass flow during load change tests.

At the starting point at $63 \%$ load, the bed temperature of the numerical analysis and the experiment agree very well, while the temperature at the top of the reactor is significantly higher in the simulation. It is also apparent that the pressure above the bed $(2.1 \mathrm{~m})$ is overestimated, while the pressure in the bed and at the top, as well as the flue gas composition agree well with the experiment. The reasons for the deviations are discussed in detail in Section 4.2.1. After $47 \mathrm{~min}$, the load is increased to $88 \%$. In the simulation, the temperatures oscillate shortly after the load changes, especially in the dense bed region. PI-controllers control the mass flows of combustion air in the model. These controllers 
cause a temporary excess/shortage of air and thus they are responsible for the temperature oscillation. Further optimization of the controller is necessary to match the air-flow of the experiment at all times. There is a very good agreement for the overall duration of the load change. In the experiment and the simulation, $75 \%$ of the absolute change in temperature is completed after 3-4 min. After $97 \mathrm{~min}$, the load is increased to $100 \%$. The load change duration is similar to the first load transient. Despite the oscillation after the load change in the numerical model, the furnace response is predicted well by the model and $75 \%$ of the new temperature level is reached after $2-3 \mathrm{~min}$. As already discussed in Section 4.2.1, the model is more accurate at higher loads with regard to the average pressure and temperature in the furnace.

The first load decreasing step (100-89\%) is performed after $182 \mathrm{~min}$. Due to the fuel mass flow fluctuations, shortly after the load change, there is a higher oxygen excess in the flue gas in the experiment compared to the simulation. When the fuel mass flow decreases slightly over time, the average oxygen excess decreases and is closer to the model prediction. This leads to a lower temperature level at the beginning of the $88 \%$ load test and an increasing temperature to the end of this test. For both, experiment and process model, the temperature difference between the $100 \%$ and $89 \%$ load test is low compared to the other tests. Therefore, and due to the fuel mass flow fluctuations, it is difficult to assess the duration of the temperature change in detail. After $264 \mathrm{~min}$, the load changes from $89 \%$ to $68 \%$ load. The temperature response directly after the load change is reproduced well by the model. However, in the experiment, there is a long period (20-25 min), where the temperature converges to the final value, which is not observed in the simulation.

Compared to the partly slowly changing temperatures, the pressures are changing very fast (a few minutes) in all load transient tests-for the experiment and the numerical model. This is because the hydrodynamic condition mainly depends on the gas velocity and the solid particle properties. It depends only indirectly on the temperature-mainly by changing gas density and viscosity. On the other hand, the temperatures do of course depend strongly on the hydrodynamic conditions. However, the new temperature levels do not adjust as quickly as the pressure, due to the heat storage capacity of the bed material and the refractory. The large fluctuations of the pressure in the experiment in areas with high solid content (bed and splash zone) are typical for a CFB. The fluctuations decrease with the height of the reactor. The fluctuations are not given in the simulation, due to its one-dimensional nature.

Concluding this, the response of pressure and temperature on positive load changes can be predicted well by the model. It is not clear if this is also valid for negative load transients, but the first response after the load change seems to be predicted with good accuracy. In future studies, the fuel mass flow including the fluctuations should be modeled with higher details to further assess the dynamic properties of the model. However, with some improvements, the model seems to be suitable to predict the load transient response of a boiler very well. Therefore, core annulus models could be used to test novel concepts to increase the maximum load ramps of CFB combustors.

\section{Conclusions}

The conclusions are as follows:

1. The average temperature in the riser is significantly higher at descending load compared to ascending loads, which is due to the heat that is stored in the refractory/bed material at high loads and released when the load decreases. The process model shows this specific characteristic of CFBs with high accuracy, especially for the bed temperature.

2. The model predicts the duration of the positive load changes correctly. A statement for negative load changes cannot be given with certainty, but the response of the furnace directly after the load change seems to be reproduced well also at negative load transients. A high level of detail is necessary when modeling the material properties of the refractory and the bed material to achieve a high agreement between experiment and simulation for the dynamic behavior. 
3. In the pilot, the freeboard temperature decreases sharply at lower loads, because the combustion reactions shift to the high-density bed. The model can reproduce this behavior well, although it overestimates the temperature in the freeboard at low loads.

4. The $\mathrm{CO}$ concentration increases at lower loads due to decreasing temperatures in the freeboard and an imperfect mixing of air and burnable components in the riser. The model neglected this imperfect mixing and was not able to show the incomplete combustion at low loads/temperatures.

5. As expected, the entrainment increases with increasing load, while the overall pressure difference from the bottom to the top only slightly changes. The APROS model with the annulus core approach overestimates the entrainment but reproduces the total pressure drop well. Improvements are necessary for future studies to match the pressure profile of the experiment with higher accuracy.

This study is relevant for future research on the flexible operation of CFB combustion regarding load change operation. The presented CFB model is highly suitable to examine concepts for accelerated load ramps. The work gives valuable concepts for, and insight into the process modeling of the CFB combustion technology. In ongoing work, the developed model is further optimized for different kinds of fuels such as refuse-derived fuel (RDF) and biomass and will be validated with experimental data of co-combustion tests with lignite and straw/RDF.

Author Contributions: Conceptualization, J.P. and F.A.; Methodology, J.P. and F.A.; Validation, J.P. and F.A.; Investigation, J.P.; Resources, B.E.; Writing-Original Draft Preparation, J.P.; Writing—Review \& Editing, J.P. and F.A.; Visualization, J.P.; Supervision, B.E. and F.A.; Project Administration, B.E.; Funding Acquisition, B.E. All authors have read and agreed to the published version of the manuscript.

Funding: This research was funded by the Research Fund for Coal and Steel (RFCS) grant number 754032 and the APC was funded by the German Research Foundation and the Open Access Publishing Fund of Technical University of Darmstadt.

Acknowledgments: Financial support is acknowledged from the RFCS project of the European Commission under grant agreement n. 754032 (FLEXible operation of FB plants co-Firing LOw rank coal with renewable fuels compensating vRES-FLEX FLORES). We acknowledge support by the German Research Foundation and the Open Access Publishing Fund of Technical University of Darmstadt.

Conflicts of Interest: The authors declare no conflict of interest.

\section{Appendix A}

Table A1. Test results at steady-state and part-loads.

\begin{tabular}{|c|c|c|c|c|c|c|c|}
\hline Property & Unit & $\begin{array}{l}\text { Tuning Point } \\
82 \% \text { Load }\end{array}$ & $\begin{array}{l}63 \% \\
\text { Load }\end{array}$ & $\begin{array}{l}88 \% \\
\text { Load }\end{array}$ & $\begin{array}{l}100 \% \\
\text { Load }\end{array}$ & $\begin{array}{l}89 \% \\
\text { Load }\end{array}$ & $\begin{array}{l}68 \% \\
\text { Load }\end{array}$ \\
\hline Temp. at $0.25 \mathrm{~m}$ & ${ }^{\circ} \mathrm{C}$ & 794.3 & 800.8 & 790.9 & 805.6 & 822.3 & 829.1 \\
\hline Temp. at $1.12 \mathrm{~m}$ & ${ }^{\circ} \mathrm{C}$ & 796.1 & 794.4 & 789.9 & 809.3 & 820.0 & 821.8 \\
\hline Temp. at $1.55 \mathrm{~m}$ & ${ }^{\circ} \mathrm{C}$ & 794.6 & 796.6 & 788.6 & 804.8 & 817.0 & 825.6 \\
\hline Temp. at $2.38 \mathrm{~m}$ & ${ }^{\circ} \mathrm{C}$ & 795.1 & 797.8 & 789.5 & 804.9 & 817.1 & 826.8 \\
\hline Temp. at $6.25 \mathrm{~m}$ & ${ }^{\circ} \mathrm{C}$ & 720.3 & 685.0 & 725.2 & 760.8 & 751.5 & 715.9 \\
\hline Temp. at $8.21 \mathrm{~m}$ & ${ }^{\circ} \mathrm{C}$ & 728.2 & 686.9 & 732.2 & 762.3 & 760.5 & 729.6 \\
\hline Temp. after cyclone & ${ }^{\circ} \mathrm{C}$ & 740.9 & 715.9 & 744.1 & 776.5 & 782.2 & 769.6 \\
\hline Pressure at $0.11 \mathrm{~m}$ & mbar & 53.3 & 45.1 & 50.0 & 55.7 & 45.0 & 51.2 \\
\hline Pressure at $0.22 \mathrm{~m}$ & mbar & 47.5 & 38.8 & 44.3 & 50.6 & 39.4 & 44.3 \\
\hline Pressure at $0.4 \mathrm{~m}$ & mbar & 34.7 & 24.1 & 31.9 & 42.3 & 28.4 & 28.7 \\
\hline Pressure at $0.58 \mathrm{~m}$ & mbar & 28.1 & 14.2 & 25.3 & 39.3 & 23.1 & 17.7 \\
\hline Pressure at $0.91 \mathrm{~m}$ & mbar & 23.8 & 9.1 & 21.3 & 36.3 & 19.8 & 10.3 \\
\hline Pressure at $1.1 \mathrm{~m}$ & mbar & 22.8 & 8.6 & 20.4 & 35.2 & 18.9 & 9.6 \\
\hline Pressure at $2.07 \mathrm{~m}$ & mbar & 19.5 & 7.2 & 17.3 & 31.2 & 16.1 & 7.9 \\
\hline Pressure at $3.42 \mathrm{~m}$ & mbar & 17.2 & 5.9 & 15.0 & 27.4 & 13.2 & 5.7 \\
\hline Pressure at $7.31 \mathrm{~m}$ & mbar & 17.4 & 6.6 & 15.2 & 27.6 & 14.1 & 7.2 \\
\hline Pressure at $8.03 \mathrm{~m}$ & mbar & 14.9 & 5.3 & 12.7 & 23.7 & 11.8 & 5.7 \\
\hline
\end{tabular}


Table A1. Cont.

\begin{tabular}{lccccccc}
\hline \multicolumn{1}{c}{ Property } & Unit & $\begin{array}{c}\text { Tuning Point } \\
\mathbf{8 2 \% \text { Load }}\end{array}$ & $\begin{array}{c}\mathbf{6 3 \%} \\
\text { Load }\end{array}$ & $\begin{array}{c}\mathbf{8 8 \%} \\
\text { Load }\end{array}$ & $\begin{array}{c}\mathbf{1 0 0 \%} \\
\text { Load }\end{array}$ & $\begin{array}{c}\mathbf{8 9 \%} \\
\text { Load }\end{array}$ & $\begin{array}{c}\mathbf{6 8 \%} \\
\text { Load }\end{array}$ \\
\hline $\mathrm{CO}_{2}$ in flue gas & $\mathrm{Vol-}_{\text {wet }}$ & 10.3 & 12.0 & 12.8 & 12.6 & 12.9 & 13.1 \\
\hline $\mathrm{O}_{2}$ in flue gas & $\mathrm{Vol-}_{\text {wet }}$ & 6.0 & 4.5 & 3.7 & 4.2 & 3.7 & 3.4 \\
\hline $\mathrm{H}_{2} \mathrm{O}$ in flue gas & $\mathrm{Vol-}_{\text {wet }}$ & 17.0 & 19.5 & 20.6 & 19.8 & 20.1 & 20.1 \\
\hline $\mathrm{CO}$ in flue gas & $\mathrm{ppm}_{\text {wet }}$ & 177.5 & 243.3 & 335.0 & 87.8 & 86.6 & 58.6 \\
\hline $\mathrm{SO}_{2}$ in flue gas & $\mathrm{ppm}_{\text {wet }}$ & 678.7 & 944.4 & 739.8 & 849.7 & 1624.8 & 1300.1 \\
\hline Flue gas flow rate & $\mathrm{Nm}^{3} / \mathrm{h}$ & 1364.5 & 921.2 & 1214.1 & 1477.7 & 1205.9 & 926.9 \\
\hline$v_{\text {avg }}$ & $\mathrm{m} / \mathrm{s}$ & 4.16 & 2.78 & 3.70 & 4.60 & 3.77 & 2.88 \\
\hline
\end{tabular}

Table A2. Bottom ash analysis.

\begin{tabular}{ccc}
\hline Property & Unit & Value \\
\hline Bulk density & $\mathrm{kg} / \mathrm{m}^{3}$ & 1350 \\
\hline Total carbon & ${ }^{\mathrm{wt}-} \mathrm{\%}_{\mathrm{dry}}$ & 0.4 \\
\hline $\mathrm{D}(10)$ & $\mathrm{mm}$ & 0.132 \\
\hline $\mathrm{D}(50)$ & $\mathrm{mm}$ & 0.211 \\
\hline $\mathrm{D}(90)$ & $\mathrm{mm}$ & 1.100 \\
\hline
\end{tabular}

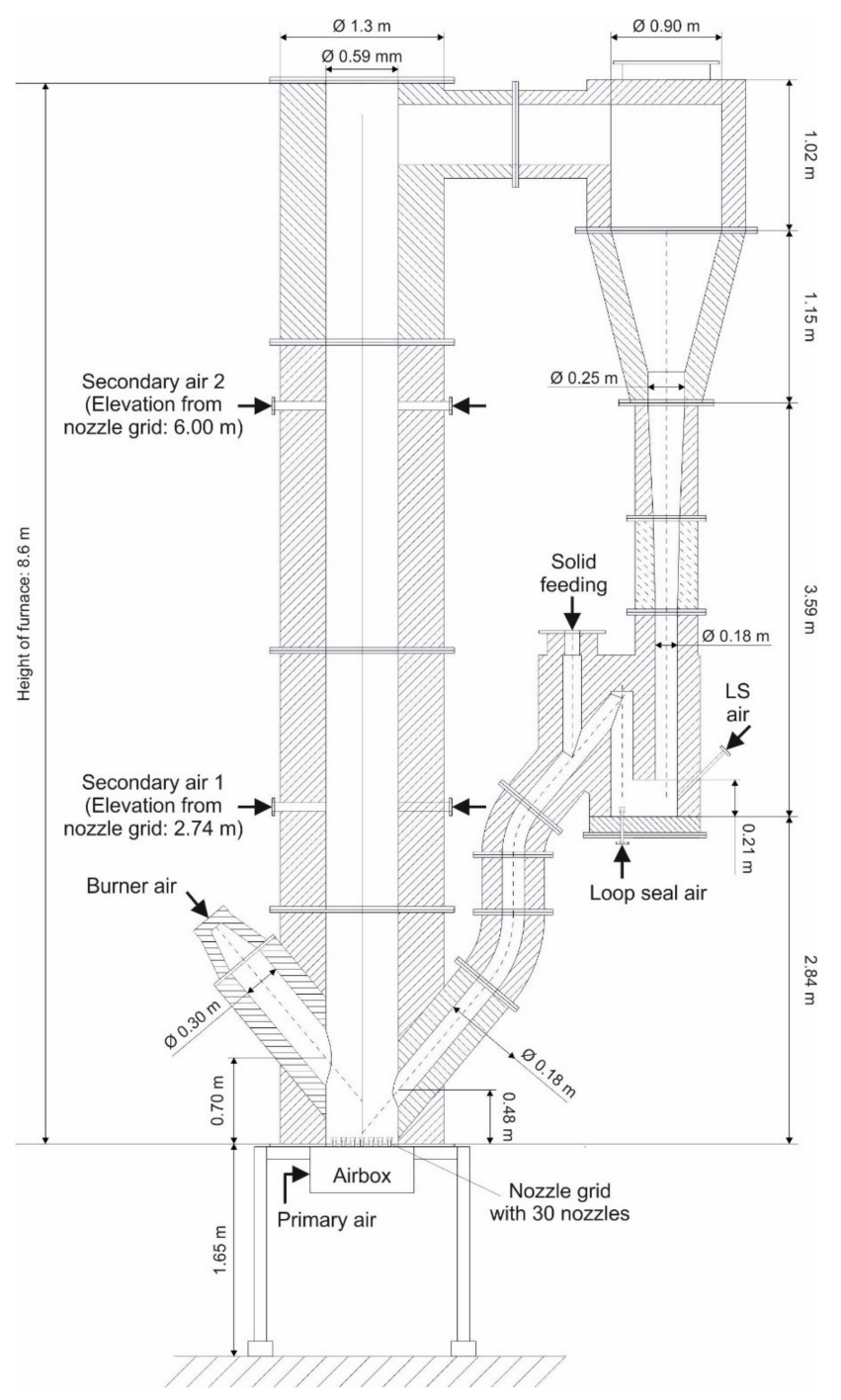

Figure A1. Detailed geometry of CFB combustor. 


\section{References}

1. REN21. Renewables 2015 Global Status Report; REN21 Secretariat: Paris, France, 2015.

2. Walter, H.; Epple, B. Numerical Simulation of Power Plants and Firing Systems; Springer: Vienna, Austria, 2017.

3. Yates, J.G.; Lettieri, P. Fluidized-Bed Reactors: Processes and Operating Conditions; Springer International Publishing: Basel, Switzerland, 2016.

4. Oka, S. Fluidized Bed Combustion; Marcel Dekker, Inc.: New York, NY, USA, 2003.

5. Nuortimo, K.; Eriksson, T.; Nevalainen, T. Large Scale Utility CFB Technology in Worlds Largest Greenfield $100 \%$ Biomass Power Plant; Sumitomo Heavy Industries, Ltd.: Espoo, Finland, 2017.

6. Lockwood, T. Techno-Economic Analysis of PC Versus CFB Combustion Technology, Ccc/226; IEA Clean Coal Centre: London, UK, 2013.

7. Miller, B.G. Clean Coal Engineering Technology; Elsevier: Oxford, UK, 2010.

8. Basu, P. Combustion of coal in circulating fluidized-bed boilers: A review. Chem. Eng. Sci. 1999, 54, 5547-5557. [CrossRef]

9. Mills, S.J. Integrating Intermittent Renewable Energy Technologies with Coal-Fired Power Plant, Ccc/189; IEA Clean Coal Centre: London, UK, 2011.

10. Stefanitsis, D.; Nesiadis, A.; Koutita, K.; Nikolopoulos, A.; Nikolopoulos, N.; Peters, J.; Ströhle, J.; Epple, B. Simulation of a CFB boiler integrated with a thermal energy storage system during transient operation. Front. Energy Res. 2020, 8, 169.

11. Gao, M.; Hong, F.; Liu, J. Investigation on energy storage and quick load change control of subcritical circulating fluidized bed boiler units. Appl. Energy 2017, 185, 463-471. [CrossRef]

12. Alobaid, F.; Mertens, N.; Starkloff, R.; Lanz, T.; Heinze, C.; Epple, B. Progress in dynamic simulation of thermal power plants. Prog. Energy Combust. Sci. 2017, 59, 79-162. [CrossRef]

13. Henderson, C. Increasing the Flexibility of Coal-Fired Power Plants; IEA Clean Coal Centre: London, UK, 2014; p. 15.

14. Huttunen, M.; Peltola, J.; Kallio, S.; Karvonen, L.; Niemi, T.; Ylä-Outinen, V. Analysis of the processes in fluidized bed boiler furnaces during load changes. Energy Procedia 2017, 120, 580-587. [CrossRef]

15. Wu, Y.; Liu, D.; Ma, J.; Chen, X. Three-Dimensional Eulerian-Eulerian Simulation of Coal Combustion under Air Atmosphere in a Circulating Fluidized Bed Combustor. Energy Fuels 2017, 31, 7952-7966. [CrossRef]

16. Xie, J.; Zhong, W.; Shao, Y.; Liu, Q.; Liu, L.; Liu, G. Simulation of combustion of municipal solid waste and coal in an industrial-scale circulating fluidized bed boiler. Energy Fuels 2017, 31, 14248-14261. [CrossRef]

17. Farid, M.M.; Jeong, H.J.; Kim, K.H.; Lee, J.; Kim, D.; Hwang, J. Numerical investigation of particle transport hydrodynamics and coal combustion in an industrial-scale circulating fluidized bed combustor: Effects of coal feeder positions and coal feeding rates. Fuel 2017, 192, 187-200. [CrossRef]

18. Kettunen, A.; Hyppanen, T.; Kirkinen, A.-P.; Maikkola, E. Model-Based Analysis of Transient Behavior of Large Scale CFB Boilers. In Proceedings of the International Conference on Fluidized Bed Combustion, Jacksonville, FL, USA, 18-21 May 2003; pp. 523-531.

19. Selcuk, N.; Ozkan, M. Simulation of circulating fluidized bed combustors firing indigenous lignite. Int. J. Therm. Sci. 2011, 50, 1109-1115. [CrossRef]

20. Starkloff, R.; Alobaid, F.; Karner, K.; Epple, B.; Schmitz, M.; Boehm, F. Development and validation of a dynamic simulation model for a large coal-fired power plant. Appl. Therm. Eng. 2015, 91, 496-506. [CrossRef]

21. Lappalainen, J.; Tourunen, A.; Mikkonen, H.; Hänninen, M.; Kovács, J. Modelling and dynamic simulation of a supercritical, oxy combustion circulating fluidized bed power plant concept—Firing mode switching case. Int. J. Greenh. Gas Control 2014, 28, 11-24. [CrossRef]

22. Kaikko, J.; Mankonen, A.; Vakkilainen, E.; Sergeev, V. Core-annulus model development and simulation of a CFB boiler furnace. Energy Procedia 2017, 120, 572-579. [CrossRef]

23. Grace, J.R.; Knowlton, T.; Avidan, A. Circulating Fluidized Beds; Blackie Academic and Professional: London, UK, 1997.

24. APROS. Apros 6 Feature Tutorial; Apros: Seoul, Korea, 2018; pp. 1-520.

25. Lappalainen, J.; Lalam, V.; Charreire, R.; Ylijoki, J. Dynamic modelling of a CFB boiler including the solids, gas and water-steam systems. In Proceedings of the 12th International Conference on Fluidized Bed Technology (CFB), Krakow, Poland, 23-27 May 2017; pp. 321-328. 
26. Lappalainen, J.T.; Hiidenkari, H.; Tuuri, S.; Ritvanen, J. Dynamic Core-Annulus Model for Circulating Fluidized Bed Boilers. In Proceedings of the Nordic Flame Days 2019, Turku, Finland, 28-29 August 2019.

27. Hänninen, M. Phenomenological Extensions to APROS Six-Equation Model. Non-Condensable Gas, Supercritical Pressure, Improved CCFL and Reduced Numerical Diffusion for Scalar Transport Calculation; VTT: Espoo, Finland, 2009.

28. Hänninen, M.; Ylijoki, J. The One-Dimensional Separate Two-Phase Flow Model of APROS; VTT: Espoo, Finland, 2008.

29. Starkloff, R.; Postler, R.; Al-Maliki, W.A.K.; Alobaid, F.; Epple, B. Investigation into Gas Dynamics in an Oxyfuel Coal Fired Boiler during Master Fuel Trip and Blackout. J. Process Control 2016, 41. [CrossRef]

30. Schuhbauer, C.; Angerer, M.; Spliethoff, H.; Kluger, F.; Tschaffon, H. Coupled simulation of a tangentially hard coal fired $700{ }^{\circ} \mathrm{C}$ boiler. Fuel 2014, 122, 149-163. [CrossRef]

31. Hentschel, J.; Zindler, H.; Spliethoff, H. Modelling and transient simulation of a supercritical coal-fired power plant: Dynamic response to extended secondary control power output. Energy 2017, 137, 927-940. [CrossRef]

32. Alobaid, F.; Al-Maliki, W.A.K.; Lanz, T.; Haaf, M.; Brachthäuser, A.; Epple, B.; Zorbach, I. Dynamic simulation of a municipal solid waste incinerator. Energy 2018, 149, 230-249. [CrossRef]

33. Mikkonen, H.; Lappalainen, J.; Kuivalainen, R. Modelling and dynamic studies of the second generation oxy-fired CFB boiler. In Proceedings of the 22nd International Conference on Fluidized Bed Conversion, Turku, Finland, 14-17 June 2015.

34. Al-Maliki, W.A.K.; Alobaid, F.; Kez, V.; Epple, B. Modelling and dynamic simulation of a parabolic trough power plant. J. Proces Control 2016, 39, 123-138. [CrossRef]

35. Al-Maliki, W.A.K.; Alobaid, F.; Starkloff, R.; Kez, V.; Epple, B. Investigation on the dynamic behaviour of a parabolic trough power plant during strongly cloudy days. Appl. Therm. Eng. 2016, 99, 114-132. [CrossRef]

36. Henrion, T.; Ponweiser, K.; Band, D.; Telgen, T. Dynamic simulation of a solar power plant steam generation system. Simul. Model. Pract. Theory 2013, 33, 2-17. [CrossRef]

37. Kurki, J. Simulation of thermal hydraulics at supercritical pressures with APROS. In Proceedings of the International Youth Nuclear Congress (IYNC 2008), Interlaken, Switzerland, 20-26 September 2008.

38. Arkoma, A.; Hänninen, M.; Rantamäki, K.; Kurki, J.; Hämäläinen, A. Statistical analysis of fuel failures in large break loss-of-coolant accident (LBLOCA) in EPR type nuclear power plant. Nucl. Eng. Des. 2015, 285, 1-14. [CrossRef]

39. Molerus, O.; Wirth, K.-E. Heat Transfer in Fluidized Beds; Chapman \& Hall: London, UK, 1997.

40. Lyngfelt, A.; Leckner, B. Sulphur capture in circulating fluidized-bed boilers: Can the efficiency be predicted? Chem. Eng. Sci. 1999, 54, 5573-5584. [CrossRef]

41. Makarytchev, S.; Cen, K.; Luo, Z.; Li, X. High-temperature sulphur removal under fluidized bed combustion conditions-A chemical interpretation. Chem. Eng. Sci. 1995, 50, 1401-1407. [CrossRef]

42. Mattisson, T.; Lyngfelt, A. A sulphur capture model for circulating fluidized-bed boilers. Chem. Eng. Sci. 1998, 53, 1163-1173. [CrossRef]

43. Wang, C.; Jia, L.; Tan, Y.; Anthony, E. The effect of water on the sulphation of limestone. Fuel 2010, 89, 2628-2632. [CrossRef]

(C) 2020 by the authors. Licensee MDPI, Basel, Switzerland. This article is an open access article distributed under the terms and conditions of the Creative Commons Attribution (CC BY) license (http://creativecommons.org/licenses/by/4.0/). 